Canadian

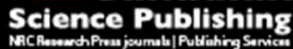

Canadian Geotechnical Journal Revue canadienne de géotechnique

The Influence of Structure on the Behavior of a Saturated Clayey Loess

\begin{tabular}{|r|l|}
\hline Journal: & Canadian Geotechnical Journal \\
\hline Manuscript ID & cgj-2015-0200.R1 \\
\hline Danuscript Type: & Article \\
\hline Complete List of Authors: & $\begin{array}{l}\text { Xu, Ling; Xi'an Jiaotong University, formerly City University of Hong Kong } \\
\text { and Institute of Geology and Geophysics, Chinese Academy of Sciences, } \\
\text { Department of Civil Engineering } \\
\text { Coop, Matthew; City University of Hong Kong, }\end{array}$ \\
\hline Keyword: & compressibility, shear strength, fabric/structure of soils, Laboratory tests \\
\hline \multicolumn{2}{|c}{} \\
\hline
\end{tabular}




\title{
The Influence of Structure on the Behavior of a Saturated
}

\section{Clayey Loess}

\author{
L.Xu ${ }^{*}$ and M.R.Coop ${ }^{+}$
}

*Corresponding author: suyu820@163.com Institute of Geology and Geophysics, Chinese Academy of Sciences, formerly City University of Hong Kong 


\section{Abstract}

An intensive experimental investigation by means of triaxial and oedometer tests was performed on a clayey loess that was retrieved from two depths at a location on the southern Chinese Loess Plateau. Intact and reconstituted samples were used to identify the effects of the natural structure on soil behavior in saturated conditions. The behavior in compression was clearly affected by structure with the intact samples reaching well-defined gross yield points outside the intrinsic compression line of the reconstituted soil, after which the compression paths converged towards the intrinsic compression lines, behavior which is consistent with destructuration. However, very high stresses were required to give complete convergence. Similarly the triaxial tests that were carried out at lower stress levels also did not give convergence of the critical states so that different critical state lines could be defined for the intact and reconstituted soils. This was consistent with qualitative observations from scanning electron micrographs that natural elements of fabric and possibly bonding persisted even after triaxial shearing. The effects of structure at the two depths on the compression and shearing behavior were slightly larger for the shallower samples. Despite the very different genesis of the soils, it was found that similar frameworks could be applied to those used for sedimentary clays and that the degree of structure was equivalent to a clay of medium sensitivity.

Keywords: compressibility, shear strength, fabric/structure of soils, Laboratory tests 


\section{INTRODUCTION}

During the Pleistocene, loess transported by wind was deposited widely in China (Heller and Liu 1982; Kukla and An 1989). As a result of this genesis, the Aeolian soils deposited under free-fall typically form highly open structures with the interstitial clay-particles congregating at the silt-particles contacts. The finer particles and particle aggregates have low settling velocities, and they were generally deposited further from the source area. The finer particle content of loess on the Chinese Loess Plateau increases from northwest to southeast (Fig.1). They are classified progressively as sandy loess, silty loess and clayey loess (Liu 1985). It is the clayey loess from Jingyang on the southeast margins of the plateau (Fig.1), also investigated by Jiang et al. (2014), which has been used here to identify in detail the influence of structure on its behavior.

Loess soils around the world are frequently partially saturated in-situ and much research has focused on their collapse on wetting (e.g. Rogers et al. 1994; Muñoz-Castelblanco et al. 2011; Jiang et al. 2012). The element of structure that is linked to that collapse is typically thought to be inter-particle bonding, but researchers are not unanimous about the origins of the inter-particle bonds. Some have emphasized clay particles, often in aggregated form, linking larger silt grains (e.g. Barden et al. 1973; Delage et al. 2005), but others refer to calcite bonding, dissolved salts or iron oxide (e.g. Derbyshire et al. 1995; Jiang et al. 2012). While a loss of bonding may be the cause of the collapse, its magnitude is related to the open fabric of 
the loess and many authors have used Scanning Electron Microscopy, Mercury Intrusion Porosimetry or Computed Tomography to investigate this (e.g. Delage et al. 2005; Wen and Yan 2013; Jiang et al. 2014).

There has been a significant amount of work examining the effects of structure on other aspects of the behavior of partially saturated loess, not just collapse (e.g. Wen and Yan 2013). While some researchers have suggested a more or less complete loss of bonding on saturation (Dijkstra et al. 2000; Dijkstra 2001), others have found significant effects of structure even in the saturated soils (e.g. Feda et al. 1993; Jiang et al. 2014). Reviewing existing data (Hu et al. 2004; Chen et al. 2006; Shao et al. 2006; Li and Yao 2009), Liu et al. (2013) identified the similarity between the behavior of intact loess soils and natural clays, with similar processes of destructuration under load leading to the behavior of the intact soil converging with that of the reconstituted. However, there have been relatively few attempts to identify comprehensively the effects of structure in loess following the same types of techniques used for sedimentary clays (e.g. Burland 1990; Cotecchia and Chandler 2000) or sands (e.g. Cuccovillo and Coop 1999).

Loess composition in China varies not only with location but also with depth and these variations represent changing geological environments during the Quaternary, especially changes to the nature, size or location of the source area and/or winds (Liu 1985; Ding et al. 1997). While many researchers have also reported variations of 
mechanical properties with depth (Liu 1985) these studies have generally not highlighted the role of structure and how that changes with depth. It is possible that the broadly common origin of the soils might give rise to more similarity in the underlying mechanical behavior if suitable normalization for the intrinsic properties were made.

The work described herein placed particular emphasis on investigating the influences of structure and the interaction of structure with depth of burial in the context of the macro-mechanical behavior of the soil in a saturated state. While the partial saturation that is typical of loess in situ has important engineering consequences and interacts with the effects of structure, a complete investigation of the saturated behavior is a necessary first step to understanding the mechanics. Most loess research in China concentrates on the silty loesses because of the collapse that they undergo during saturation, but here a clayey loess has been tested that is not subject to collapse, but which will be shown nevertheless to have a significant effect of structure on its behavior.

\section{MATERIALS AND PROCEDURES}

The samples tested were obtained from south Jingyang platform at depths below ground level of $20 \mathrm{~m}$ and $50 \mathrm{~m}$, both depths belonging to Middle Pleistocene $\left(\mathrm{Q}_{2}\right)$. The loess of the Chinese plateau is normally consolidated (Shao et al. 2011), so these should be the maximum depths of burial. Both soils were retrieved from areas cut for soil extraction and although the locations were about $7 \mathrm{~km}$ apart the ground levels of 
the plateau were within about $2 \mathrm{~m}$ of each other. A block sampling method was adopted clearing about $1 \mathrm{~m}$ of superficial loess prior to excavation. The blocks were carefully trimmed by hand and sealed using layers of cling-film (plastic wrap) and wax.

The index properties for the two materials are presented in Table 1 . The dry density of the shallower loess is $1500-1520 \mathrm{~kg} / \mathrm{m}^{3}$ with a void ratio of $0.81-0.83$. The deeper loess is significantly denser than the shallow, with a dry density of $1580-1590 \mathrm{~kg} / \mathrm{m}^{3}$ with a void ratio of $0.72-0.74$. Figure 2 shows the particle size distributions determined by conventional sieving and sedimentation. The amount of silt in the two soils is similar at about $75-77 \%$ but the deeper sample is slightly better graded over the silt size range. The clay contents were the same for the two soils at about $18 \%$. Mineralogical analysis showed that the predominant mineral for the soil fraction is quartz, with smaller amounts of albite and calcite with significant quantities of clay minerals (Table 2). Both materials have relatively low plasticities but that at $50 \mathrm{~m}$ is slightly higher, perhaps the result of the small difference in grading or the slightly higher montmorillonite content. Both materials plot slightly above the A-Line on the plasticity chart, and are classified as CL, inorganic clays of low to medium plasticity, but are quite close to the ML region for inorganic silts.

Figure 3 shows typical SEM images of the intact loess specimens for the two depths tested, taken on broken horizontal and vertical surfaces. Many of the particles have a 
platy shape and these tend to be more visible as flat surfaces in the horizontal plane than the vertical, especially for the $20 \mathrm{~m}$ sample, indicating a predominant horizontal particle orientation, as might be expected. The particles also tend to be clustered into aggregates, but at $20 \mathrm{~m}$ the aggregate particles seem more loosely packed than those at $50 \mathrm{~m}$. Both samples have larger voids between the aggregates and these are also more evident at $20 \mathrm{~m}$. The $20 \mathrm{~m}$ sample therefore has a clearly more open texture. A higher magnification image in Fig.3(e) shows an amorphous coating over many of the particles. This was found at both depths, and while it could create some cement bonding between particles it was local in nature not pervasive throughout the samples. The 50m block sample had a homogenous meso-scale fabric at the scale visible to the naked eye, but the $20 \mathrm{~m}$ sample had a number of visible voids (Fig.4), probably of biogenic origin.

The intact triaxial samples were carefully trimmed vertically on a hand lathe to the required dimensions of $38 \mathrm{~mm}$ diameter and $76 \mathrm{~mm}$ length, while the intact oedometer samples were trimmed directly into the $50 \mathrm{~mm}$ confining ring on the lathe applying some downward pressure on the ring while trimming slightly ahead of the cutting edge. The reconstituted samples for both triaxial and oedometer tests were made from the trimmings and were created by the moist tamping method, taking care to use sufficient compaction to avoid any macro-voids remaining and using the undercompaction method of Ladd (1978). 
Tables 3 and 4 give summary data for all the tests. For the oedometer tests the accuracy of the initial specific volumes, $v(=1+\mathrm{e})$ was ensured by using two methods of calculation, the first method measuring the initial dimensions and weights of the samples and the second the water contents at the ends of the tests together with the volumetric strains measured during testing. Any tests for which the differences between the two values were more that \pm 0.01 were discarded. An average value of $\mathrm{v}$ is reported in Table 3 and these should therefore be accurate to better than \pm 0.005 . The intact soil was partially saturated with a degree of saturation typically of about $60 \%$ for the $20 \mathrm{~m}$ sample and $70 \%$ for the $50 \mathrm{~m}$. The reconstituted samples were also initially partially saturated because of their creation by wet compaction. While the immersion in the water bath was found sufficient to give good final saturation of the oedometer samples, the triaxial samples were saturated under back pressure until B values of at least $95 \%$ were achieved.

In the oedometer tests care was taken that the stresses applied to the intact samples during saturation caused neither significant swelling or compression, to prevent destructuration. The vertical stress was therefore varied to hold a constant height during the initial stages of the test. The stresses required were quite low, at around $10 \mathrm{kPa}$, but as will be shown later, the swelling line gradients of the samples were small, so there was not a strong tendency either to swell or compress at low stress levels. Similar initial stresses were applied to the intact triaxial samples, because during saturation the true volumetric strains are unknown, as the volumetric strain 
measured by the back pressure volume gauge has a component arising from the dissolution and/or compression of air within the sample. Since there was no local measurement of volume change on the apparatus, the values of specific volume reported in Table 4 for the triaxial tests at the end of saturation are based solely on the final water content measurements, together with the volumetric strain during the test after saturation. The triaxial samples were all isotropically compressed in small steps to a variety of stress levels and then sheared in compression either undrained or drained.

\section{INFLUENCE OF STRUCTURE ON COMPRESSION BEHAVIOUR}

The one dimensional and isotropic compression data for reconstituted samples and intact samples are plotted in Fig.5. The reconstituted samples were made with a variety of initial specific volumes to check whether the various compression paths would converge onto unique Intrinsic Compression Lines (ICL), or if there was any evidence of transitional behavior with non-convergent compression curves (e.g. Altuhafi et al. 2010; Shipton and Coop 2012). With the exception of one isotropic test that may not have been loaded quite far enough to reach the ICL, or may have some slight inaccuracy in v, all the tests on reconstituted samples define unique ICLs in both isotropic and one-dimensional loading. Although there are some small variations in the properties such as grading and mineralogy, these seem not to affect the ICLs that are similar for both depths. 
The data for the two intact block samples both clearly reach states outside the ICLs, in one-dimensional and isotropic loading which is an indication of the effects of structure. These tests were started at relatively low effective stresses for two reasons, firstly so that the pre-yield behavior could be observed in compression and secondly to avoid any possible collapse that might have occurred had the samples been saturated at their in-situ stress levels. At the original in-situ stresses the intact samples would have states well outside the ICLs and so collapse could have been an issue.

The compression plots show that even for saturated loess the effects of structure can be very significant and that although the geological origin is very different, the effects of structure on compression are broadly similar in character and magnitude to those for sedimentary clays (e.g. Cotecchia and Chandler 2000; Hosseini Kamal et al. 2014). The intact soil compression paths reach states to the right of the ICL and gross yield points can be clearly identified as the points where the stress-volume behavior changes significantly, after which the paths tend to converge with their respective ICLs for isotropic or one-dimensional loading. The term "gross yield" is adopted as used in the sensitivity framework of Cotecchia and Chandler (2000) because, as they pointed out the strains below them are usually not purely elastic.

Burland (1990) proposed normalizing the compression data of intact clay samples relative to the gradient and intercept of the reconstituted soil in order to highlight the effects of structure to give void index, $I_{v}$ : 
$I_{v}=\frac{e-e_{100}^{*}}{e_{100}^{*}-e_{1000}^{*}}$

where $\mathrm{e}^{*}{ }_{100}$ and $\mathrm{e}^{*}{ }_{1000}$ are the void ratios on the ICL at 100 and $1000 \mathrm{kPa}$. This method was originally proposed for clays, but in Fig.6(a) it has been applied to these loess soils, although the curvature of the ICL from Fig.5(a) is slightly smaller than for the sedimentary clays analyzed by Burland. The data for the intact samples resemble those of Feda et al. (1993) for a European loess that they also normalized using void index.

The history of suction in-situ is not known but the water table is well below the sample depths (Lei 2001; Xu et al. 2011). The gross yield points are quite close the estimated past total stresses and so the effects of in-situ suction cannot have been large or those yield stresses would have been increased under the combination of the total stress and suction. The relatively stiff initial loading behavior and the small volumetric strains that occur prior to reaching stress levels equal to the in-situ total stress are indications that the samples were not badly disturbed either through sampling or laboratory preparation.

The gross yield points and possible in-situ maximum stresses both plot close to the Sedimentation Compression Line (SCL) defined by Burland for the in-situ states of normally consolidated clays. As Cotecchia and Chandler highlighted the SCL of Burland corresponds to soils having a sensitivity of about 5 and since these samples 
yield at slightly lower stresses, the sensitivities are moderate and slightly less than 5 . In comparison the swell sensitivity (Schmertmann 1969), defined as the ratio of swelling indices of the reconstituted and intact soils, $\mathrm{C}_{\mathrm{sr}} / \mathrm{C}_{\mathrm{s}}$, has values of about unity prior to gross yield, and this does not change after yield. This would imply that there is no effect of structure, which is unusual and seems not to agree with the clear yield in compression.

As highlighted by Coop and Cotecchia (1995) and Baudet and Stallebrass (2004) one key difficulty of Burland's void index is that it is only defined in terms of vertical stress for one dimensional compression and a new parameter $v_{n}$, was therefore defined in terms of invariants, so that isotropic and one-dimensional compression data as well as shearing data may all be compared:

$v_{n}=\exp \left(\frac{\left.\ln (v)-N^{*}\right)}{\lambda^{*}}\right)$

Figure 6(b) shows the volumetric compression data, normalized using $v_{n}$, for both the natural and reconstituted loess. To allow for the curvature that Burland highlighted in Intrinsic Compression Lines when examined over an extended pressure range and that can be seen in the oedometer data in Fig.5(a), they are assumed to be straight when a logarithmic specific volume axis is used, as suggested by Butterfield (1979):

$\ln v=N^{*}-\lambda^{*} \ln p^{\prime}$

where values of 0.833 and 0.061 have been used for $\mathrm{N}^{*}$ and $\lambda^{*}$ respectively. Although 
the equations are defined in natural $\operatorname{logs}, \log _{10}$ scales are shown for convenience on Fig.6(b). This method of normalization uses the isotropic normal compression line of the reconstituted soil rather than the one dimensional as the reference condition and so these data plot on the straight ICL, with a gradient of -1 , with the one dimensional compression data for the reconstituted plotting slightly below. In calculating p' for the oedometer tests the simple assumption has been made that $\mathrm{K}_{0}=1-\sin \phi^{\prime}$. Over an extended pressure range the isotropic and one-dimensional data diverge slightly and so in choosing the gradient of the ICL the oedometer data, which cover a much greater pressure range have been trusted more than the isotropic compression. This slight difference in gradients may result from end friction in the triaxial tests, which had conventional platens. Comparing the oedometer and isotropic compression tests for the intact samples, the gross yield points are fairly similar, as are the rates of convergence towards the ICL, indicating that destructuration occurs at fairly similar rates in one-dimensional and isotropic loading for these soils.

The comparison of the data for the $20 \mathrm{~m}$ and $50 \mathrm{~m}$ samples gives an insight into the evolution of structure with depth and so the origins of the structure, not previously investigated for loess soils. The similarity of the intrinsic properties corresponds to there being only relatively small differences in grading, mineralogy and index properties, and indicates that the nature of the loess deposited at the two depths and times was fairly similar. It also means that the comparison of the compression behavior can be made equally well on either the normalized plots (Fig.6) or non-normalized (Fig.5) since a key reason for normalization is to remove the effects of composition. The two block samples have slightly different initial specific volumes, the deeper loess having a slightly lower value as expected, but in both 
one-dimensional and isotropic compression the gross yield points for the two depths are at quite similar distances outside the ICL, and those in one-dimensional compression are close to the SCL. After yield, the rates of convergence with the ICL are also similar for the two depths. These similarities confirm that the soil has a predominantly sedimentation structure, as defined by Cotecchia and Chandler (2000), so that the formation of the structure should have been coincident with rather than subsequent to burial. The differences in in-situ specific volume and yield stress are thus simply those expected from the different burial depths. Sedimentation structure is typical of younger, normally or lightly overconsolidated clays, as opposed to geologically older overconsolidated clays that generally possess some form of post-sedimentation structure formed after burial.

\section{INFLUENCE OF STRUCTURE ON SHEARING BEHAVIOUR}

\section{Stress-Strain Behavior}

Figure 7 presents typical stress-strain data for the intact and reconstituted samples; the changes of pore pressures are normalized by initial effective confining pressure, $\mathrm{p}_{0}^{\prime}$. The initial states of each tests are on the isotropic ICL for the reconstituted samples and above the ICL for the intact and so the volumetric strains and pore pressure responses during shearing are compressive for both. Most of the tests were stopped at axial strains of at least $40 \%$ at which point they had generally reached constant stress and volume states, although there are some small continued changes for some of the intact samples. The application of such large strains caused some barreling of the samples, although the strongly contractive volume changes meant that this was less noticeable in the drained tests. 
The behavior of the intact soil is distinctly stiffer initially than the reconstituted for similar stress levels, again with clear gross yield points similar to those seen in compression at which points the stress-strain behavior softens significantly. These gross yield points are present even if the initial state is slightly post-gross yield in compression, for example at 400kPa Test 50m_UU01. At initial states further beyond gross yield, for example at $650 \mathrm{kPa}$ in test $50 \mathrm{~m} \_$UD03 the gross yield point during shearing is absent. For drained conditions the intact soil continues to strain harden after gross yield while for undrained it strain softens rapidly, a feature that is not seen for the reconstituted soil and might again be attributed to the effects of structure.

In Fig. 8 the stress-strain data are represented by a stress ratio, $\mathrm{q}^{\prime} / \mathrm{p}^{\prime}$. Again the intact samples can be seen to be stiffer for similar loading conditions, but it is also clear that while the $20 \mathrm{~m}$ samples tend towards a final ratio $\mathrm{M}$ of 1.35 those from $50 \mathrm{~m}$ have a lower final value of around 1.25 , most tests being within about \pm 0.05 of these values. These values of $\mathrm{M}$ correspond to critical state angles of shearing resistance, $\phi_{\text {cs }}^{\prime}$ of $33.4^{\circ}$ and $31.1^{\circ}$ respectively. The lower $\mathrm{M}$ at $50 \mathrm{~m}$ depth is consistent with the slightly higher plasticity.

\section{Stress-Dilatancy Behavior}

The stress-dilatancy relationships for the drained tests on the reconstituted loess from 20m in Fig.9(a) give a straight relationship at larger strains. In the absence of elastic 
shear and bulk moduli, total strains have been plotted, the shear strain being calculated as $\varepsilon_{\mathrm{s}}=\varepsilon_{\mathrm{v}}-\varepsilon_{\mathrm{a}} / 3$, which assumes isotropy. The gradients have been taken by regression over short sections of the $\varepsilon_{\mathrm{s}}: \varepsilon_{\mathrm{v}}$ graph. There is some scatter in the data at low stress ratios, because the rate of dilation is calculated as the ratio of two small values of strain. When the data for the intact samples from $20 \mathrm{~m}$ are compared with the reconstituted (Figs.9b) the relationships are significantly different, reflecting the influence of the natural structure. At small strains the paths initially reach higher stress ratios than the equivalent reconstituted soil, but then tend towards the same critical state $\mathrm{M}$ at large strains. For the $50 \mathrm{~m}$ depth the data are a little less clear, and there is little significant difference between the intact and reconstituted samples. The tendency towards the lower M value of 1.25 seen in Fig. 8 occurs relatively late in some tests. There was no clear visual evidence of strain localization so this is unlikely to be the cause.

\section{Critical States}

In Fig. 10 the undrained stress paths highlight the differences between the intact and reconstituted samples that indicate effects of structure, with the intact samples giving stress paths that are significantly more strain softening. The end of test states have been assumed to be critical states and these again confirm the different $\mathrm{M}$ values.

For consistency with the $\mathrm{v}_{\mathrm{n}}$ graph the shearing paths are shown in the lnv : lnp' plane in Fig.11. The paths followed by many of the intact samples are more strongly 
compressive, with greater volume changes for the drained tests and higher pore pressures for the undrained since they start with higher initial specific volumes. Zhou et al. (2014) also highlighted the strongly strain-softening behavior of an intact loess that resulted from initial states far above the critical state line, which they attributed to structure, but they could not confirm this as they did not make comparisons with reconstituted soils. Even if the paths for the intact samples indicate a strongly compressive behavior, the end of test states give a critical state line (CSL) that lies higher than that of the reconstituted samples.

The CSLs for both reconstituted and intact samples $\left(\mathrm{CSL}_{\mathrm{r}}\right.$ and $\left.\mathrm{CSL}_{\mathrm{i}}\right)$ are the same for the two depths in either the lnv:lnp' plane or $\ln v_{n}: \ln p^{\prime}$ plane (Fig.12) and in the normalized plane they are parallel to the ICL. It is perhaps surprising that the relatively small differences in the grading and index properties of the soil at the two depths has some effect on the critical states in the stress plane, $q^{\prime}: p^{\prime}$ but not in the compression plane lnv:lnp', but this is consistent with there being no effect also on either the isotopic or one-dimensional intrinsic compression behavior.

The spacing between the CSLs for the intact and reconstituted soil in terms of specific volume is around 0.08 , which would represent a volumetric strain of about $5 \%$ for the initial specific volumes of the samples. Although there is some very small continued volume change at the end of the tests for some of the drained tests on intact samples (Fig.7c) it is clear that incomplete testing could not be the cause of there being two 
different CSLs. Provided that a soil has a homogenous structure, shearing should eventually lead to a unique critical state when all elements of the initial structure are erased and the soil should tend towards not only constant stresses and volumes, but also a constant fabric. However, Nougier-Lehon et al. (2005) demonstrated that the strains needed to reach a constant fabric could be very large indeed. Many models for structured soils assume ultimate convergence of the intact with the reconstituted states (e.g. Liu et al. 2013). In contrast, to account for more stable elements of fabric that could not be removed by the strain levels imposed by triaxial testing, in their framework Cotecchia and Chandler (2000) assumed that the CSL of the intact soil need not correspond with that of the reconstituted. This was implemented in their constitutive model by Baudet and Stallebrass (2004) by permitting an offset between the CSLs of the intact and reconstituted soil, so that as an intact soil destructures it need not collapse back to the CSL of the reconstituted soil, no matter what strains are applied. For clays several examples have been observed where robust fabrics could not be broken down by triaxial shearing, requiring the definition of different CSLs for intact and reconstituted soils (Rampello and Silvestri 1993; Coop and Cotecchia 1995; Fearon and Coop 2000).

This lack of convergence of critical states during shearing contrasts with the better convergence of the oedometer tests on Figs.5 and 6, although close inspection shows that at higher pressures the critical states for the intact and reconstituted soils do plot slightly closer together, perhaps the start of some convergence of the CSLs. The more 
evident convergence of the oedometer test data may be the result of the much larger stress levels applied and larger volumetric strains. In many constitutive models for structured soils the volumetric strains are assumed to play a greater role in the breakdown of the structure than the shear strains (e.g. Callisto et al. 2002), while in some the destructuration is solely related to volumetric strains (e.g. Lagioia and Nova 1995; Baudet and Ho 2004).

Figure 13 shows SEM images of the intact and reconstituted soils from $20 \mathrm{~m}$ after triaxial shearing. The intact sample (Fig.13a and b) has a much denser fabric than before shearing (Fig.3a and b) as a result of the strong volumetric compression it has experienced. There is still the evident preferential orientation of the particles in the horizontal plane and areas of the amorphous coating, possibly cementing, could still be found (Fig.13c). The reconstituted soil was sheared drained at $400 \mathrm{kPa}$ while the intact was sheared drained at $450 \mathrm{kPa}$. Nevertheless the reconstituted soil seems still to have a denser fabric than the intact as might be expected from the lower specific volumes at critical state (Fig.13d and e). The difference between the horizontal and vertical surfaces is also less evident and areas of possible cementing were less easily identified.

\section{Normalized Boundary Surfaces}

In Fig.14 the stress paths have been normalized for volume by an equivalent pressure taken on the CSL, $\mathrm{p}_{\mathrm{cs}}$, defined as: 
$p_{\mathrm{CS}}^{\prime}=\exp \left(\frac{\Gamma^{*}-\ln V}{\lambda^{*}}\right)$

where $\lambda^{*}$ and $\Gamma^{*}$ are the gradient of the CSL and its intercept at intercept at $1 \mathrm{kPa}$ in the lnv : lnp' plane. To reduce some small scatter of the normalized paths when identifying the state boundary surfaces, it has been assumed that any slight difference in the final specific volume and that on the chosen CSL (either intrinsic or intact) in Fig.11 arises from small inaccuracies in specific volume and so the final values have been adjusted to lie on those lines. Because of the two different $\mathrm{M}$ values for the two depths, the values of $\mathrm{q} / \mathrm{p}_{\mathrm{cs}}^{\prime}$ have been further divided by $\mathrm{M}$ so that the CSL plots at $1,1$.

The paths for the reconstituted soil in Fig. 14a define a clear reconstituted or intrinsic state boundary surface $\left(\mathrm{SBS}_{\mathrm{r}}\right)$. The shape of this intrinsic surface shares more similarity with those of sands (e.g. Coop and Lee 1993) than those of clays (e.g. Hosseini-Kamal et al. 2014), since the spacing between the isotropic ICL and the $\mathrm{CSL}_{\mathrm{r}}$ is relatively large at about 2.6 when expressed as a ratio of stresses, and the $\mathrm{CSL}_{\mathrm{r}}$ lies to the left of an apex of the boundary surface (i.e. a maximum value of $\left.\mathrm{q}^{\prime} / \mathrm{Mp}_{\mathrm{cs}}^{\prime}\right)$. The normalized paths of the undrained tests tend also to plot inside the boundary surface defined by the drained tests, so that Rendulic's principle is not obeyed. In sands, Coop and Lee (1993) attributed these features to particle breakage but none could be detected in these tests and similar behavior has been found in gap graded residual soils by Ferreira and Bica (2006) also without breakage. 
In Fig. $14 \mathrm{~b}$ the stress paths of the tests on intact samples have been normalized with respect to the $\mathrm{CSL}_{\mathrm{i}}$. These are compared with the intrinsic $\mathrm{SBS}_{\mathrm{r}}$ normalized with respect to the $\mathrm{CSL}_{\mathrm{r}}$, i.e. two different CSLs are assumed. The differences between undrained and drained tests are much accentuated with the normalized drained tests for low to medium stress levels reaching large stress ratios before a gross yield is seen after which the path drops rapidly back towards the critical state, a feature that can also be seen in the lnv : lnp' plane (Fig.11). The sizes of the intact state boundary surfaces $\left(\mathrm{SBS}_{\mathrm{i}}\right)$ are both considerably larger than the $\mathrm{SBS}_{\mathrm{r}}$, again indicating the effects of structure. Once isotropic compression prior to shearing takes the initial state past the gross yield, the normalized stress paths tend to collapse back towards the $\mathrm{SBS}_{\mathrm{r}}$, giving the paths that are more rounded with gross yield at lower stress ratios, converging with the shape of the SBSr. This behavior is again similar to cemented sands (e.g. Cuccovillo and Coop, 1999) or structured clays (Cotecchia and Chandler 2000). Figure 14(c) compares the two boundary surfaces when they are both normalized with respect to the intrinsic critical state line, emphasizing the separation of the two surfaces in volumetric space.

Comparing the two depths, the intrinsic behavior demonstrated by the normalized stress paths of the reconstituted samples (Fig.14a) is again very similar, apart from the different $\mathrm{M}$ values. For the intact samples the $\mathrm{SBS}_{\mathrm{i}}$ have similar shapes, but the larger $\mathrm{SBS}_{\mathrm{i}}$ for the $20 \mathrm{~m}$ samples tends to indicate a stronger effect of structure at this depth. 
This can also be seen in the isotropic gross yield points in Fig.6(b) which are slightly further outside the ICL for the $20 \mathrm{~m}$ depth than for $50 \mathrm{~m}$. However, as Hosseini-Kamal et al. (2014) and Gasparre and Coop (2008) have emphasized, apparently larger effects of structure at shallower depths and higher initial specific volumes can be an artefact of this type of volumetric normalization. Older and/or more deeply buried clays, with lower in-situ $I_{v}\left(\right.$ or $v_{n}$ ) values, reach states that are not as far outside the ICL as clays with higher initial $I_{v}$, but this is generally unrelated to the relative effects of structure in shearing.

\section{CONCLUSIONS}

An investigation was made of the effects of structure in a clayey loess from the Chinese Jingyang platform has been carried out, comparing two depths within a stratum of loess that has a similar geological age and origin and reasonably homogenous composition. The deeper loess had a lower in situ specific volume and was slightly more plastic, but otherwise the effects of structure on the larger strain behavior were quite similar, the shallower loess generally having a slightly greater effect of structure. The intact structure of the soil caused stiffer initial behavior in shearing, defining gross yield points that could be seen in both compression and shearing that marked the onset of destructuration. Although of a very different genesis, and having a low plasticity, the behavior of the loess could be analyzed within the same framework as is commonly used for sedimentary clays and the effects of structure were broadly similar to those in clays of medium sensitivity. Some elements 
of structure were relatively robust and could not be easily broken down unless loaded to very large stress levels in the oedometer. At the low to medium stress levels used in the triaxial tests two different critical state lines could be defined from the end of test states, with little evidence of their convergence with continued shear strain. This was confirmed qualitatively by observations of the persistence of differences of fabric and possibly some bonding after shearing.

\section{ACKNOWLEDGEMENTS}

The work was supported by the Natural Science Foundation of China (Project No. 51109199) and the Hong Kong Scholars Program. The first author would like to express his sincere thanks to Dr. Fanyu Zhang of Lanzhou University for his help in some laboratory testing on loess index properties, and Prof. Sun Jimin of the Institute of Geology and Geophysics, Chinese Academy of Sciences for his help in drawing the map of loess distribution.

\section{NOMENCLATURE}

$\mathrm{C}_{\mathrm{s}} \quad$ swelling index of intact soil

$\mathrm{C}_{\mathrm{sr}} \quad$ swelling index of reconstituted soil

e voids ratio

$\mathrm{I}_{\mathrm{V}} \quad$ void index (Eq.1)

$\mathrm{K}_{0} \quad$ coefficient of earth pressure

$\mathrm{N}^{*} \quad$ intercept at $1 \mathrm{kPa}$ of isotropic ICL in lnv : lnp' plane (Eq.3)

$\mathrm{p}^{\prime} \quad$ mean normal effective stress

$\mathrm{p}_{\mathrm{cs}}^{\prime} \quad$ equivalent value of $\mathrm{p}^{\prime}$ taken on CSL (Eq.4)

$\mathrm{p}_{0}^{\prime} \quad$ mean normal effective stress at start of shearing

q deviatoric stress

$\mathrm{u} \quad$ pore pressure

v specific volume $(=\mathrm{e}+1)$

$\mathrm{V}_{\mathrm{n}} \quad$ normalized specific volume (Eq.2)

$\Gamma^{*} \quad$ intercept of the CSL at $1 \mathrm{kPa}$ in $\operatorname{lnv}: \operatorname{lnp}$ plane

$\lambda \quad$ gradient of ICL or CSL in $\mathrm{v}:$ Inp' plane

$\lambda^{*} \quad$ gradient of ICL or CSL in lnv : lnp' plane (Eq.3) 
$\sigma_{\mathrm{v}}^{\prime} \quad$ vertical effective stress in oedometer

CSL critical state line

ICL isotropic intrinsic compression line

SCL sedimentation compression line

\section{REFERENCES}

Altuhafi F., Baudet B.A. and Sammonds P. 2010. The mechanics of subglacial sediment: an example of new "transitional behaviour". Canadian Geotechnical Journal 47(7): 775-790.

Barden L., McGown A. and Collins K. 1973. The collapse mechanism in partly saturated soil. Eng. Geol., 7, 49-60.

Baudet, B.A. and Ho, E.W.L. 2004. On the behaviour of deep-ocean sediments. Géotechnique, 54(9), 571-580.

Baudet, B. and Stallebrass, S. 2004. A constitutive model for structured clays. Géotechnique, 54(4), 269-278.

Burland, J.B. 1990. On the compressibility and shear strength of natural soils. Géotechnique 40(3), 329-378.

Butterfield, R. 1979. A natural compression law for soils (an advance on e - $\log \mathrm{p}^{\prime}$ ). Géotechnique, 26(4), 469-480.

Callisto, L, Gajo, A, and Wood, D.M. 2002. Simulation of triaxial and true triaxial tests on natural and reconstituted Pisa clay. Géotechnique, 52(9), 649-666.

Chen, C., Zhu, Z. and Gao, P. 2006. Research on relationship between structure and deformation property of intact loess. Rock and Soil Mechanics, 27(11), 1892-1896.

Coop, M.R. and Cotecchia, F. 1995. The compression of sediments at the archaeological site of Sibari. Proc. 11th ECSMFE, Copenhagen, 8, 19-26.

Coop, M.R. and Lee, I.K. 1993. The Behaviour of Granular Soils at Elevated Stresses. In "Predictive Soil Mechanics" Houlsby, G.T. \& Schofield, A.N. eds. (Thomas Telford, London) (Proc.C.P.Wroth Memorial Symposium, 1992), 186-198.

Cotecchia, F. and Chandler, R.J. 2000. A general framework for the mechanical behaviour of clay. Géotechnique 50(4), 431-447.

Cuccovillo, T. and Coop, M.R. 1999. On the mechanics of structured sands. Géotechnique, 49(6), 741-760. 
Delage, P., Cui, Y.J. and Antoine, P. 2005. Geotechnical problems related with loess deposits in Northern France. Proc. Int. Conf. on Problematic Soils, Eastern Mediterranean University, Famagusta, N. Cyprus, 1-24.

Derbyshire E., Meng X., Wang J., Zhou Z. and Li B. 1995. Collapsible loess on the loess plateau of China. In Genesis and Properties of Collapsible Soils, E. Derbyshire et al. eds, Kluwer Academic Publishers. 267-293.

Dijkstra, T.A. 2001. Geotechnical thresholds in the Lanzhou loess of China. Quaternary International, 76/77, 21-28.

Dijkstra, T.A., Rappange, F.E., van Asch, T.W.J., Li, Y.J. and Li, B.X. 2000. Laboratory and in situ shear strength parameters of Lanzhou loess. In: Derbyshire, E., Meng, X.M., Dijkstra, T.A. (Eds.), Landslides in the Thick Loess of North-West China, Chapter 5. Wiley, Chichester, 131-172.

Ding, Z., Sun, J., Rutter, N.W., Rokosh, D. and Liu , T. 1997. Changes in Sand Content of Loess Deposits along a North-South Transect of the Chinese Loess Plateau and the Implications for Desert Variations. Quaternary Research, 52, 56-62.

Fearon, R.E. and Coop, M.R. 2000. Reconstitution: what makes an appropriate reference material? Géotechnique, 50(4), 471-477.

Feda, J., Bohac, J. and Herle, I. 1993. Compression of collapsed loess: Studies on bonded and unbonded soils. Eng. Geol., 34, 95-103.

Ferreira, P.M.V. and Bica, A.V.D. 2006. Problems in identifying the effects of structure and critical state in a soil with a transitional behavior. Géotechnique 56(7), 445-454.

Gasparre, A. and Coop, M. R. 2008. The quantification of the effects of structure on the compression of a stiff clay. Canadian Geotech. J. 45(9), 1324-1334.

Heller, F. and Liu, T.S. 1982. Magnetostratigraphical dating of loess deposits in China Nature. Vol. 300, 431-433.

Hosseini-Kamal, R., Coop, M.R. and Jardine, R.J. and Brosse, A. 2014. The post-yield behaviour of four Eocene-to-Jurassic UK stiff clays. Géotechnique, 64(8), 620-634.

Hu, Z., Shen Z. and Xie, D. 2004. Deformation properties of structural loess. Chinese J. Rock Mechs \& Eng., 23(24), 4143-4145.

Jiang, M., Hu, H. and Liu, F. 2012. Summary of collapsible behaviour of artificially structured loess in oedometer and triaxial wetting tests. Can. Geotech. J. 49, 1147-1157. 
Jiang, M.J., Zhang, F.G., Hu, H.J., Cui, Y.J., Peng, J.B. 2014. Structural characterization of natural loess and remolded loess under triaxial tests. Eng. Geol., 181, 249-260.

Kukla, G. and An, Z. 1989. Loess stratigraphy in Central China. Palaeogeography, Palaeoclimatology, Palaeoecology, 72, 203-225.

Ladd, R. S. 1978. Preparing test specimens using under-compaction. Geotech. Testing J., 1(1), 16-23.

Lagioia, R. and Nova, R. 1995. An experimental and theoretical study of the behaviour of a calcarenite in triaxial compression. Géotechnique, 45(4), 633-648.

Lei, X. Y. 2001. The Geo-Hazards and Human Activities on Chinese Loess Platform: The Geological Publishing House, Beijing, 244 pp.

Li, J. and Yao, Y. 2009. Critical state model of Ko consolidated structure loess. J. Xi'an Univ. Arch. \& Tech. (Natural Science Edition), 42(4), 533-537.

Liu, T.S. (Ed.) 1985. Loess and the Environment. Science Press, Beijing, 215 pp.

Liu, M. D., Liu, J., Horpibulsuk, S. and Huang, W. 2013. Simulating the stress and strain behavior of loess via SCC model. In C. Leung, S. Goh \& R. Shen (Eds.), 18th Southeast Asian Geotechnical Conference: Geotechnical Infrastructure. Singapore: Research Publishing. 455-460.

Muñoz-Castelblanco, J., Delage, P., Pereira, J.M. and Cui, Y.J. 2011. Some aspects of the compression and collapse behaviour of an unsaturated natural loess. Géotechnique Letters, 1(2), 17-22.

Nougier-Lehon, C., Vincens, E. and Cambou, B. 2005. Structural changes in granular materials: the case of irregular polygonal particles. Intl. J. Solids and Structures, 42 (24-25), 6356-6375.

Rampello, S. and Silvestri, F. 1993. The stress-strain behaviour of natural and reconstituted samples of two overconsolidated clays. In Geotechnical engineering of hard soils soft rocks (eds A. Anagnostopoulos et al.), Rotterdam: Balkema. 769-778.

Rogers, C.D.F., Dijkstra, T.A. and Smalley, I.J. 1994. Hydroconsolidation and subsidence of loess: Studies from China, Russia, North America and Europe. Eng. Geol., 37(2), 83-113.

Schmertmann, J. H. 1969. Swell sensitivity. Géotechnique 19(4), 530-533.

Shao, S., Luo, A., Yu, Q. and Zhou F. 2006. Structural damage properties of $\mathrm{Q}_{3}$ loess under triaxial loading and moistening. Chinese J. Geotch. Eng., 28(12), 2078-2081.

Shao, S., Tao, H. and Xu, P. 2011. Discussion on research of mechanical 26 
characteristics of loess considering structural behavior and its application. Rock and Soil Mechanics, 32, Supp.2, 42-50.

Shipton, B. and Coop, M.R. 2012. On the compression behaviour of reconstituted soils. Soils \& Foundations, 52(4), 668-681.

Wen, B-P. and Yan, Y-J. 2013. Influence of structure on shear characteristics of the unsaturated loess in Lanzhou, China. Eng. Geol., 168, 46-58.

Xu, L., Dai, F., Tham, L.G., Tu, X. and Jin, Y. 2011. Landslides in the Transitional Slopes between a Loess Platform and River Terrace, Northwest China. Environmental \& Engineering Geoscience, 17(3), 267-279.

Zhou, Y.F., Tham, L.G., Yan, W.M., Dai, F.C. and Xu, L. 2014. Laboratory study on soil behavior in loess slope subjected to infiltration. Eng. Geol., 183, 31-38.

\section{List of table}

Table 1. Geotechnical index properties of the materials

Table 2. X-ray diffraction analyses of the materials

Table 3. Details of oedometer tests

Table 4. Details of the triaxial tests 


\section{List of figures}

Fig.1. Sample location of Jingyang on the south Chinese Loess Plateau

Fig.2. Particle size distributions of the loess samples

Fig.3. SEM images of the intact micro-structure of the loess(a) $20 \mathrm{~m}$ deep loess, horizontal plane; (b) 20m deep loess, vertical plane; (c) 50m deep loess, horizontal plane; (d) $50 \mathrm{~m}$ deep loess, vertical plane; (e) Higher magnification image showing coating over the particles ( $50 \mathrm{~m}$ horizontal plane)

Fig.4. Photograph showing the meso-structure of the $20 \mathrm{~m}$ loess

Fig.5. Compression curves of reconstituted and intact samples: (a) oedometer tests; (b) isotropic compression curves from triaxial tests

Fig.6. Normalized compression data for natural and reconstituted loess (a) using void index, $\mathrm{I}_{\mathrm{v}}$; (b) normalized specific volume, $\mathrm{v}_{\mathrm{n}}$

Fig.7. Typical triaxial test data (a) deviator stress-axial strain curves, (b) pore pressure responses for undrained tests (c) volume changes for drained tests. ( $\mathrm{R}^{* * *}$ reconstituted, $\mathrm{U}^{* * *}$ undisturbed, $* \mathrm{D}^{* *}$ drained, $* \mathrm{U}^{* *}$ undrained)

Fig.8. Development of stress ratio for reconstituted and undisturbed specimens

Fig.9. Stress-dilatancy data for the drained tests on (a) reconstituted specimens (20m); (b) undisturbed specimens $(20 \mathrm{~m})$; (c) reconstituted and undisturbed specimens $(50 \mathrm{~m})$

Fig.10. Stress paths for intact and reconstituted samples (a) entire range of stresses; (b) enlargement for stresses less than $600 \mathrm{kPa}$

Fig.11. Critical states line in the volumetric plane

Fig.12. Critical states line in the normalized volumetric plane

Fig.13. SEM images of samples after testing (a) 20m intact sample (No. 20m_UD03) horizontal surface; (b) $20 \mathrm{~m}$ intact sample (No. 20m_UD03) vertical surface; (c) $20 \mathrm{~m}$ intact sample (No. 20m_UD03) showing detail of coating over particles; (d) $20 \mathrm{~m}$ reconstituted sample (No. 20m_RD03) horizontal surface; (e) $20 \mathrm{~m}$ reconstituted sample (No. 20m_RD03) vertical surface

Fig.14. Normalized stress-paths of intact and reconstituted loess(a) Stress-paths of reconstituted samples normalized by $p_{c s}^{\prime}$ using the intrinsic CSL; (b) Stress-paths of intact samples normalized by $p_{c s}^{\prime}$ using intact CSL; (c) Stress-paths of intact samples normalized by $p_{c s}^{\prime}$ using intrinsic $C S L$ 
Table 1. Geotechnical index properties of the materials

\begin{tabular}{|l|l|l|l|l|l|l|}
\hline Sample & $\begin{array}{l}\text { Initial void } \\
\text { ratio }\end{array}$ & $\begin{array}{l}\text { Intact dry density } \\
{\left[\mathrm{kg} / \mathrm{m}^{3}\right]}\end{array}$ & $\begin{array}{l}\text { Specifc } \\
\text { gravity }\end{array}$ & $\begin{array}{l}\text { Liquid } \\
\text { limit }\end{array}$ & $\begin{array}{l}\text { Plastic } \\
\text { limit }\end{array}$ & $\begin{array}{l}\text { Plasticity } \\
\text { index }\end{array}$ \\
\hline JY-20m & $0.81-0.83$ & $1500-1520$ & 2.73 & 28.3 & 17.1 & 11.2 \\
\hline JY-50m & $0.72-0.74$ & $1580-1590$ & 2.74 & 35.6 & 18.5 & 17.1 \\
\hline
\end{tabular}


Table 2. X-ray diffraction analyses of the materials

\begin{tabular}{|l|l|l|l|l|l|l|l|l|l|}
\hline Sample & Quartz & Albite & Calcite & Dolomite & $\begin{array}{l}\text { Montmor- } \\
\text { illonite }\end{array}$ & Illite & Kaolinite & Chlorite & Others \\
\hline JY-20m & $35.1 \%$ & $14.9 \%$ & $16.5 \%$ & $2.3 \%$ & $4.4 \%$ & $15.5 \%$ & $3.2 \%$ & $6.1 \%$ & $2.0 \%$ \\
\hline JY-50m & $32.3 \%$ & $10.2 \%$ & $19.0 \%$ & $2.1 \%$ & $7.4 \%$ & $17.7 \%$ & $3.5 \%$ & $6.7 \%$ & $1.1 \%$ \\
\hline
\end{tabular}


Table 3. Details of oedometer tests

\begin{tabular}{lllllll}
\hline $\begin{array}{l}\text { Test } \\
\text { number }\end{array}$ & $\begin{array}{l}\text { Sample } \\
\text { depth }\end{array}$ & Sample style & $\begin{array}{l}\text { Method of sample } \\
\text { preparation }\end{array}$ & $\begin{array}{l}\text { Water } \\
\text { content }\end{array}$ & $\begin{array}{l}\text { Initial } \\
\text { specific } \\
\text { volume, } v_{0}\end{array}$ & $\begin{array}{l}\sigma_{\text {vmax }}^{\prime} \\
\text { MPa }\end{array}$ \\
\hline O1 & $20 \mathrm{~m}$ & Undisturbed & - & - & 1.822 & 7.167 \\
O2 & $50 \mathrm{~m}$ & Undisturbed & - & - & 1.710 & 7.167 \\
O3 & $20 \mathrm{~m}$ & Reconstituted & Slurry & - & 2.331 & 1.098 \\
O4 & $20 \mathrm{~m}$ & Reconstituted & Wet compaction & $10 \%$ & 1.963 & 7.167 \\
O5 & $20 \mathrm{~m}$ & Reconstituted & Wet compaction & $10 \%$ & 1.797 & 7.167 \\
O6 & $50 \mathrm{~m}$ & Reconstituted & Slurry & - & 2.151 & 1.103 \\
O8 & $50 \mathrm{~m}$ & Reconstituted & Wet compaction & $10 \%$ & 2.303 & 7.167 \\
\hline
\end{tabular}


Table 4. Details of the triaxial tests

\begin{tabular}{|c|c|c|c|c|c|c|c|}
\hline \multirow[b]{2}{*}{ Test name } & \multirow[b]{2}{*}{$\begin{array}{c}\text { Sample } \\
\text { types }\end{array}$} & \multirow[b]{2}{*}{$\begin{array}{l}\text { Shearing } \\
\text { types }\end{array}$} & \multirow[b]{2}{*}{$\begin{array}{l}\text { Specific } \\
\text { volume after } \\
\text { saturation }\end{array}$} & \multirow[b]{2}{*}{$\begin{array}{l}\text { Mean } \\
\text { effective } \\
\text { stress for } \\
\text { shearing } \\
\quad / \mathrm{kPa}\end{array}$} & \multicolumn{3}{|c|}{ Ends of test } \\
\hline & & & & & $\begin{array}{l}\text { Deviator } \\
\text { stress: } q_{\mathrm{cs}} \\
\quad / \mathrm{kPa}\end{array}$ & $\begin{array}{c}\text { Mean } \\
\text { effective } \\
\text { stress: } p_{c s}^{\prime} \\
/ \mathrm{kPa}\end{array}$ & $\begin{array}{c}\text { Specific } \\
\text { volume: } v_{\mathrm{f}}\end{array}$ \\
\hline 20m_UD01 & $\mathrm{U}$ & ICD & 1.869 & 100 & 225.9 & 172.8 & 1.661 \\
\hline $20 \mathrm{~m} \_$UD02 & $\mathrm{U}$ & ICD & 1.872 & 200 & 454.8 & 350.1 & 1.612 \\
\hline 20m_UD03 & $\mathrm{U}$ & ICD & 1.877 & 450 & 1126.3 & 826.3 & 1.508 \\
\hline 20m_UU01 & $\mathrm{U}$ & $\mathrm{ICU}$ & 1.885 & 50 & 52.8 & 36.6 & 1.835 \\
\hline $20 \mathrm{~m} \_U U 02$ & $\mathrm{U}$ & $\mathrm{ICU}$ & 1.834 & 300 & 80.3 & 56.6 & 1.774 \\
\hline 50m_UD01 & $\mathrm{U}$ & ICD & 1.772 & 200 & 419.0 & 336.7 & 1.617 \\
\hline 50m_UD02 & $\mathrm{U}$ & $\mathrm{ICD}$ & 1.778 & 420 & 811.0 & 687.0 & 1.574 \\
\hline 50m_UD03 & $\mathrm{U}$ & $\mathrm{ICD}$ & 1.755 & 650 & 1348.5 & 1092.3 & 1.500 \\
\hline 50m_UU01 & $\mathrm{U}$ & $\mathrm{ICU}$ & 1.783 & 400 & 169.3 & 128.8 & 1.726 \\
\hline 20m_RD01 & $\mathrm{R}$ & ICD & 1.941 & 120 & 294.5 & 218.9 & 1.585 \\
\hline 20m_RD02 & $\mathrm{R}$ & $\mathrm{ICD}$ & 1.864 & 250 & 579.1 & 440.6 & 1.514 \\
\hline 20m_RD03 & $\mathrm{R}$ & $\mathrm{ICD}$ & 1.918 & 400 & 1000.1 & 733.9 & 1.483 \\
\hline 20m_RD04 & $\mathrm{R}$ & $\mathrm{ICD}$ & 1.564 & 300 & 675.7 & 522.7 & 1.468 \\
\hline $\begin{array}{c}20 m_{-} \mathrm{RD} 05 \\
(\mathrm{ORC}=4)\end{array}$ & $\mathrm{R}$ & $\mathrm{ICD}$ & 1.892 & 100 & 233.3 & 179.1 & 1.589 \\
\hline 20m_RU01 & $\mathrm{R}$ & $\mathrm{ICU}$ & 1.972 & 100 & 39.1 & 30.3 & 1.748 \\
\hline 20m_RU02 & $\mathrm{R}$ & ICU & 1.698 & 200 & 131.1 & 99.9 & 1.630 \\
\hline 20m_RU03 & $\mathrm{R}$ & $\mathrm{ICU}$ & 1.695 & 100 & 94.1 & 70.9 & 1.653 \\
\hline 20m_RU04 & $\mathrm{R}$ & $\mathrm{ICU}$ & 1.906 & 300 & 137.2 & 104.3 & 1.643 \\
\hline 50m_RD01 & $\mathrm{R}$ & $\mathrm{ICD}$ & 1.879 & 100 & 209.0 & 170.3 & 1.607 \\
\hline 50m_RD02 & $\mathrm{R}$ & $\mathrm{ICD}$ & 1.901 & 300 & 710.5 & 541.2 & 1.479 \\
\hline 50m_RD03 & $\mathrm{R}$ & $\mathrm{ICD}$ & 1.936 & 500 & 1227.0 & 981.6 & 1.448 \\
\hline 50m_RU01 & $\mathrm{R}$ & $\mathrm{ICU}$ & 1.722 & 400 & 302.2 & 243.3 & 1.566 \\
\hline 50m_RU02 & $\mathrm{R}$ & $\mathrm{ICU}$ & 1.936 & 600 & 381.5 & 292.6 & 1.555 \\
\hline
\end{tabular}

Note: the test name, for example 20m_UD01, indicates the sample was $20 \mathrm{~m}$ deep from the ground surface; ICD is isotropically consolidated drained shearing; ICU is isotropically undrained shearing; "U" is undisturbed sample and " $\mathrm{R}$ " is the reconstituted sample; the method of sample preparation for all reconstituted samples is wet compaction with water content of about $10 \%$. 


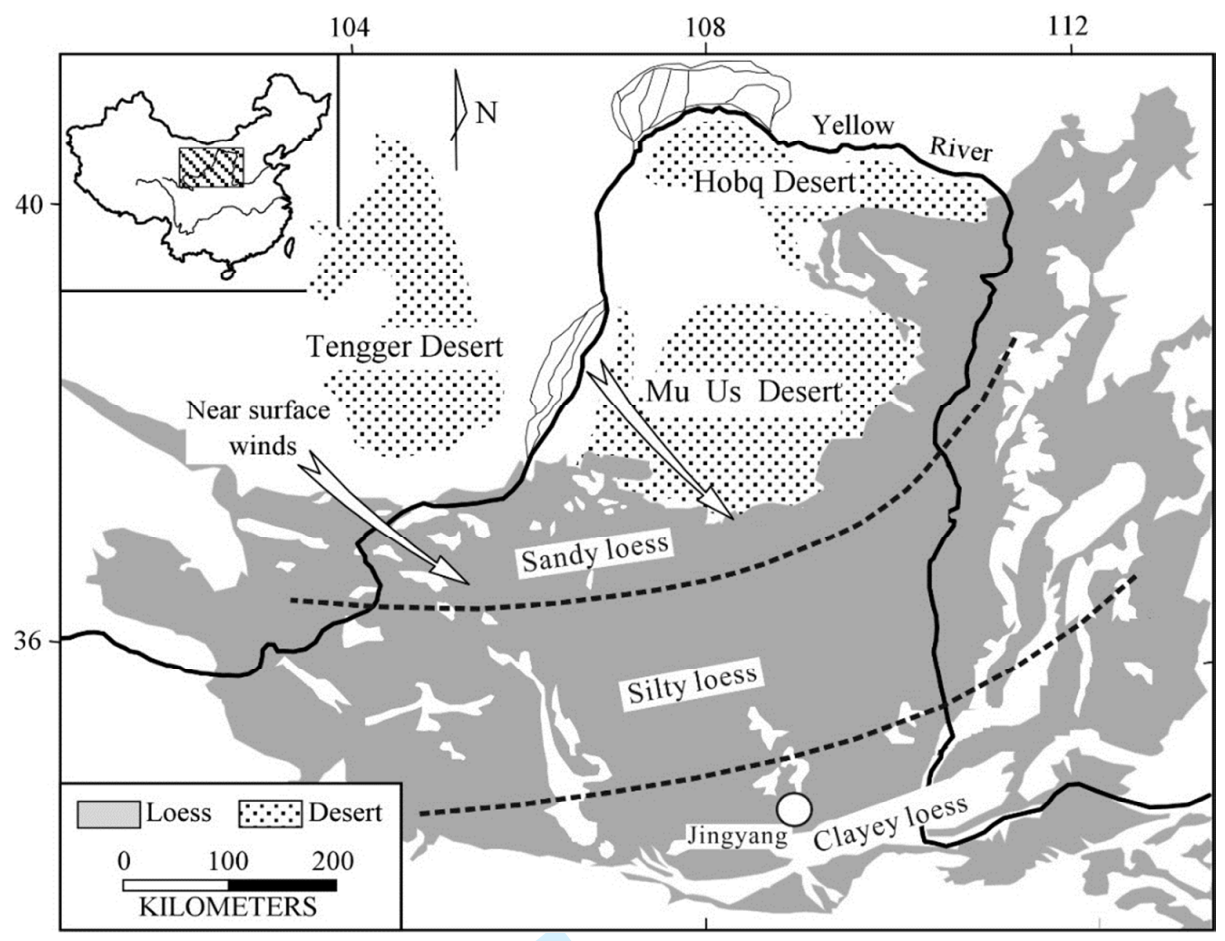

Fig. 1. Sample location of Jingyang on the south Chinese Loess Plateau 


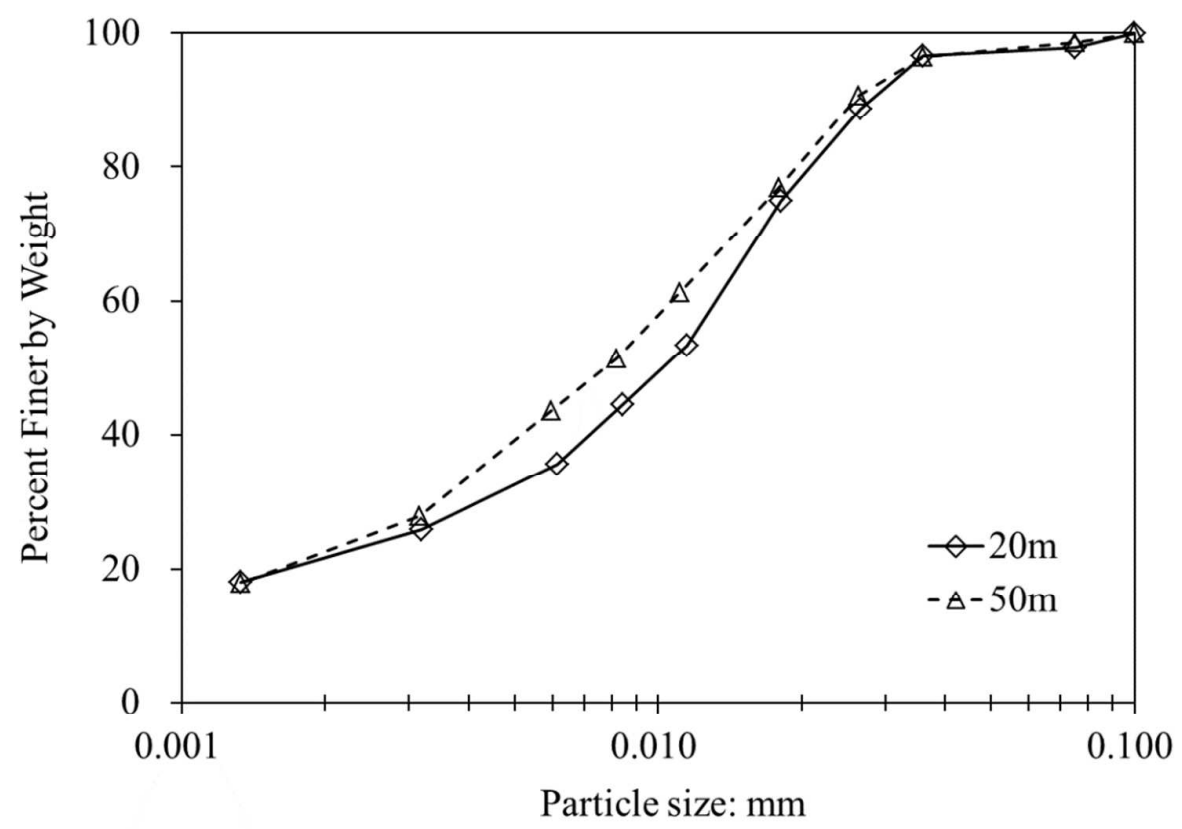

Fig. 2. Particle size distributions of the loess samples 


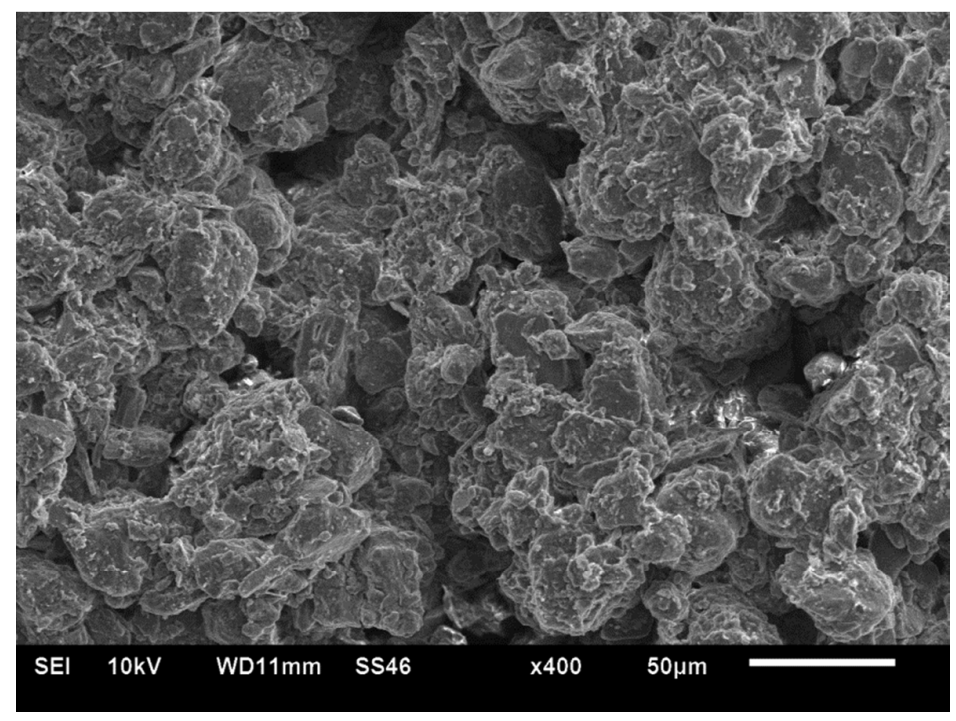

(a) 20m deep loess, horizontal plane

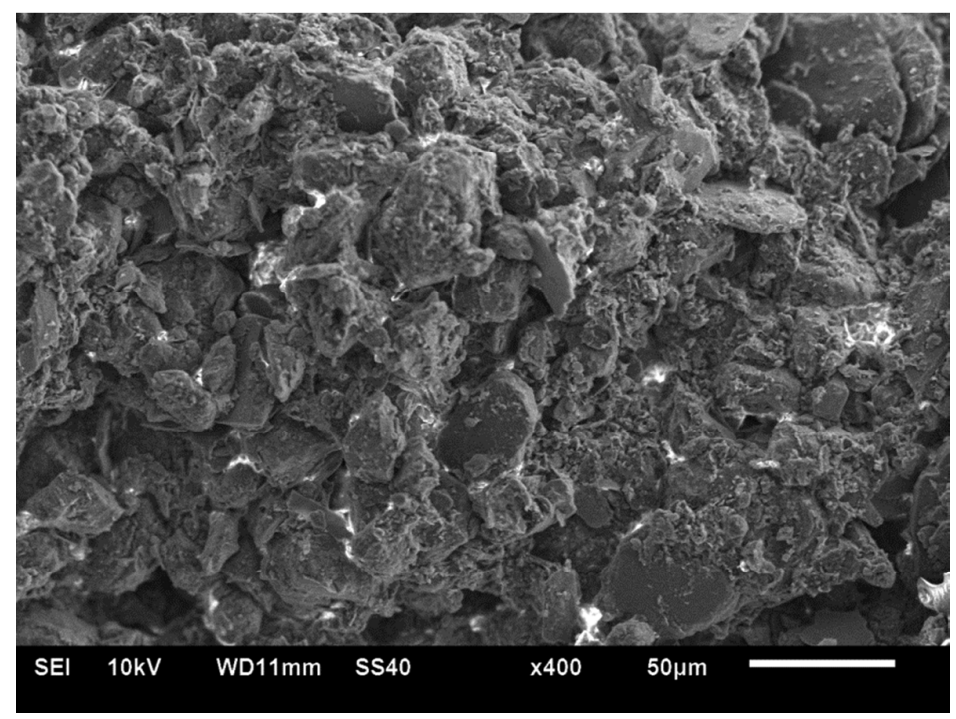

(b) $20 \mathrm{~m}$ deep loess, vertical plane 


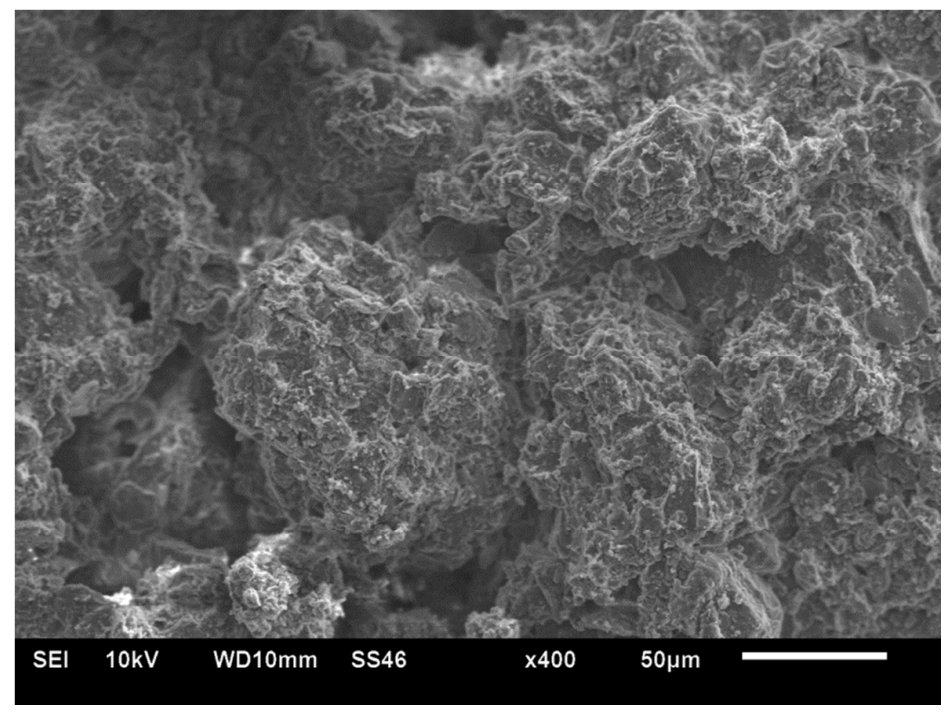

(c) $50 \mathrm{~m}$ deep loess, horizontal plane

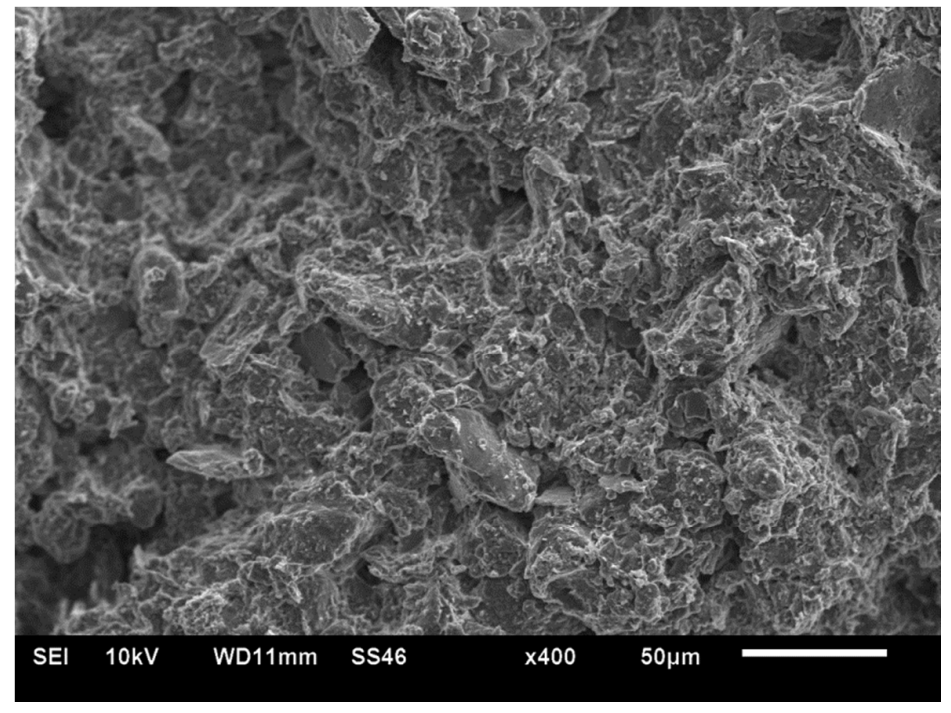

(d) 50m deep loess, vertical plane 


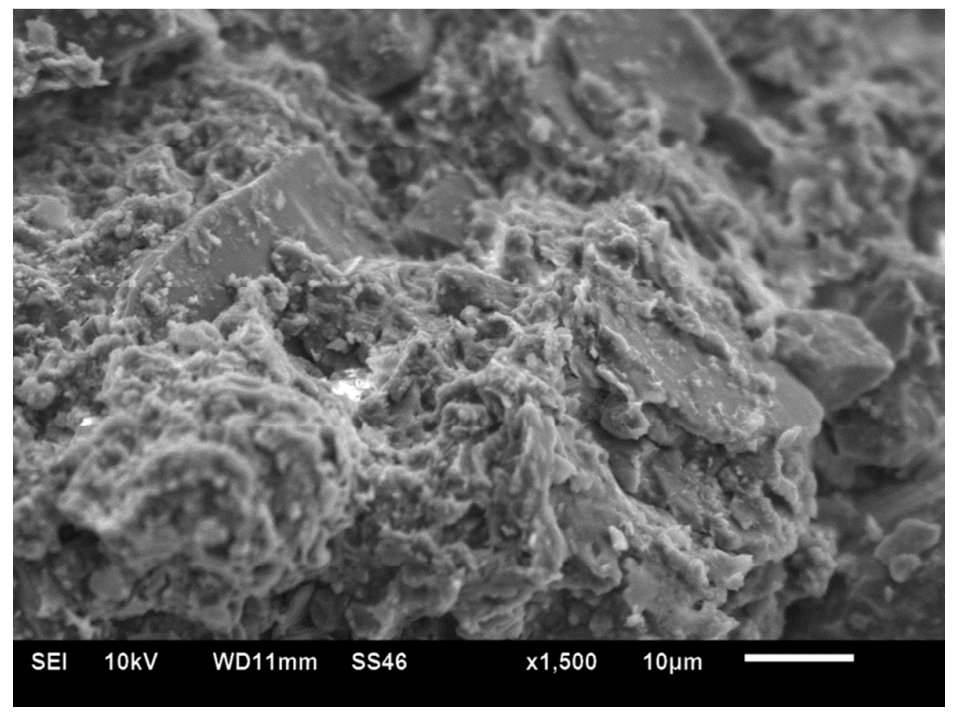

(e) Higher magnification image showing coating over the particles (50m horizontal plane)

Fig.3. SEM images of the intact micro-structure of the loess 


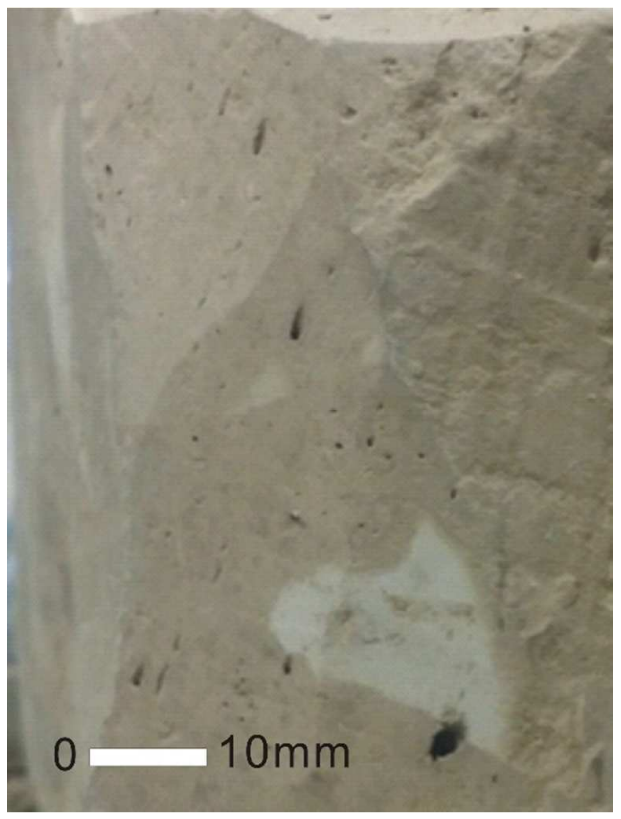

Fig.4. Photograph showing the meso-structure of the $20 \mathrm{~m}$ loess 


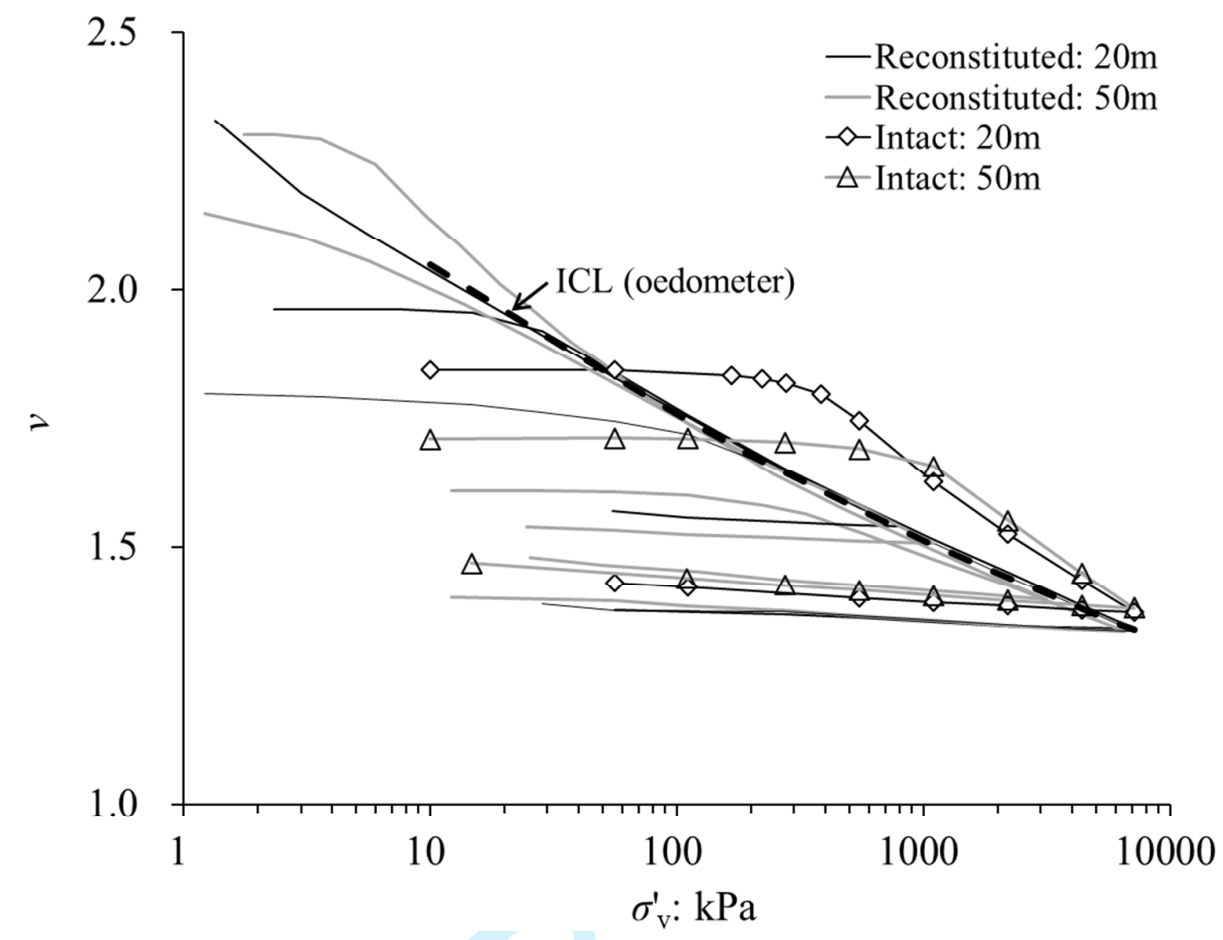

(a)

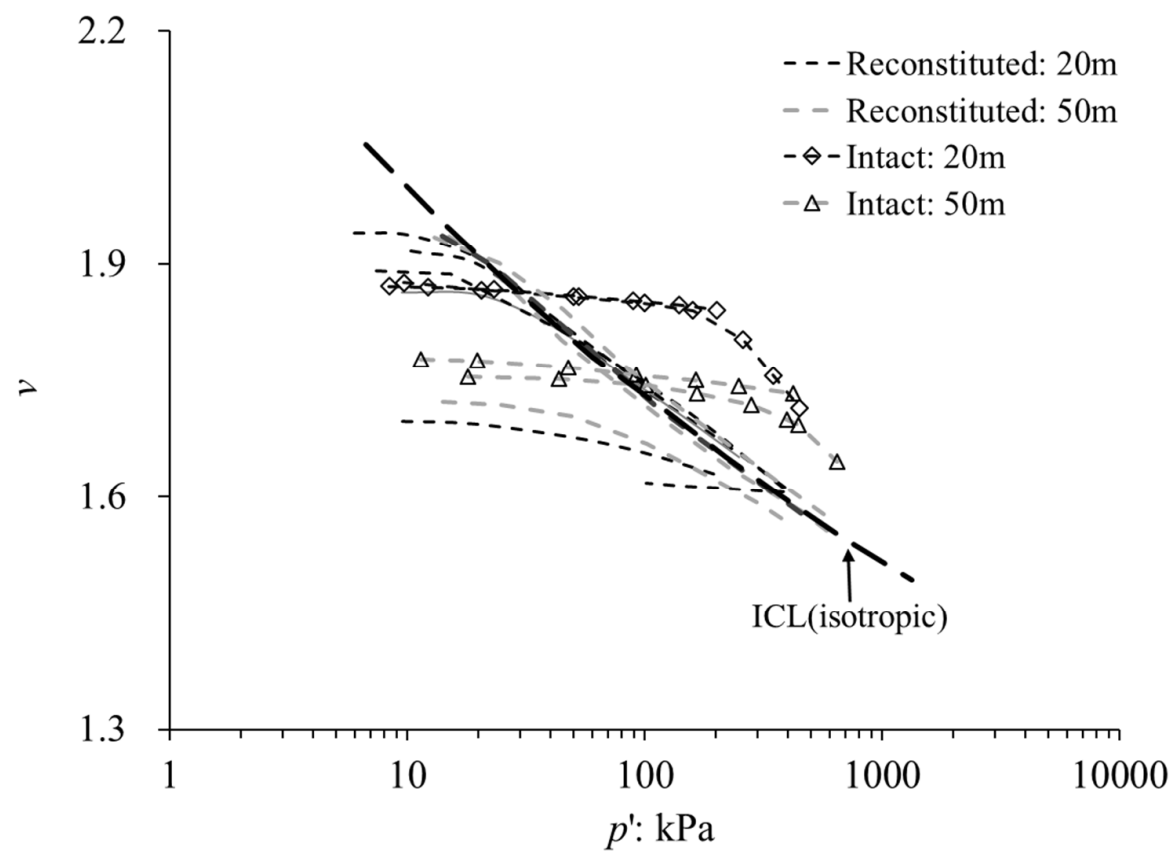

(b)

Fig. 5. Compression curves of reconstituted and intact samples: (a) oedometer tests; (b) isotropic compression curves from triaxial tests 


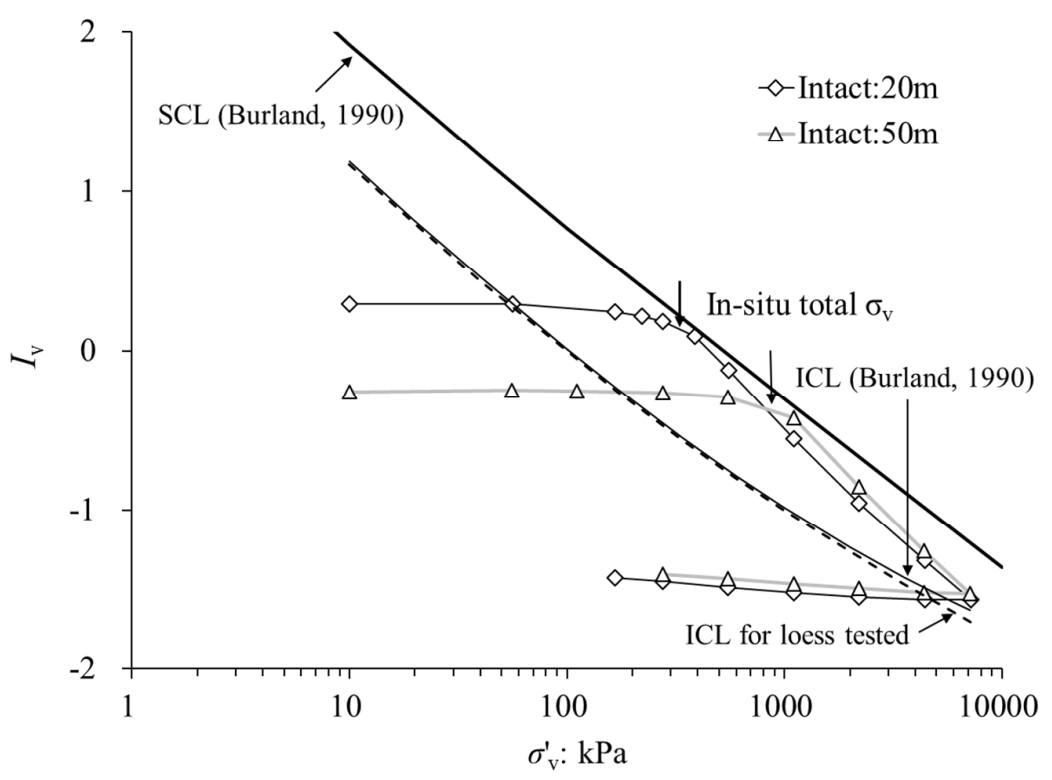

(a)

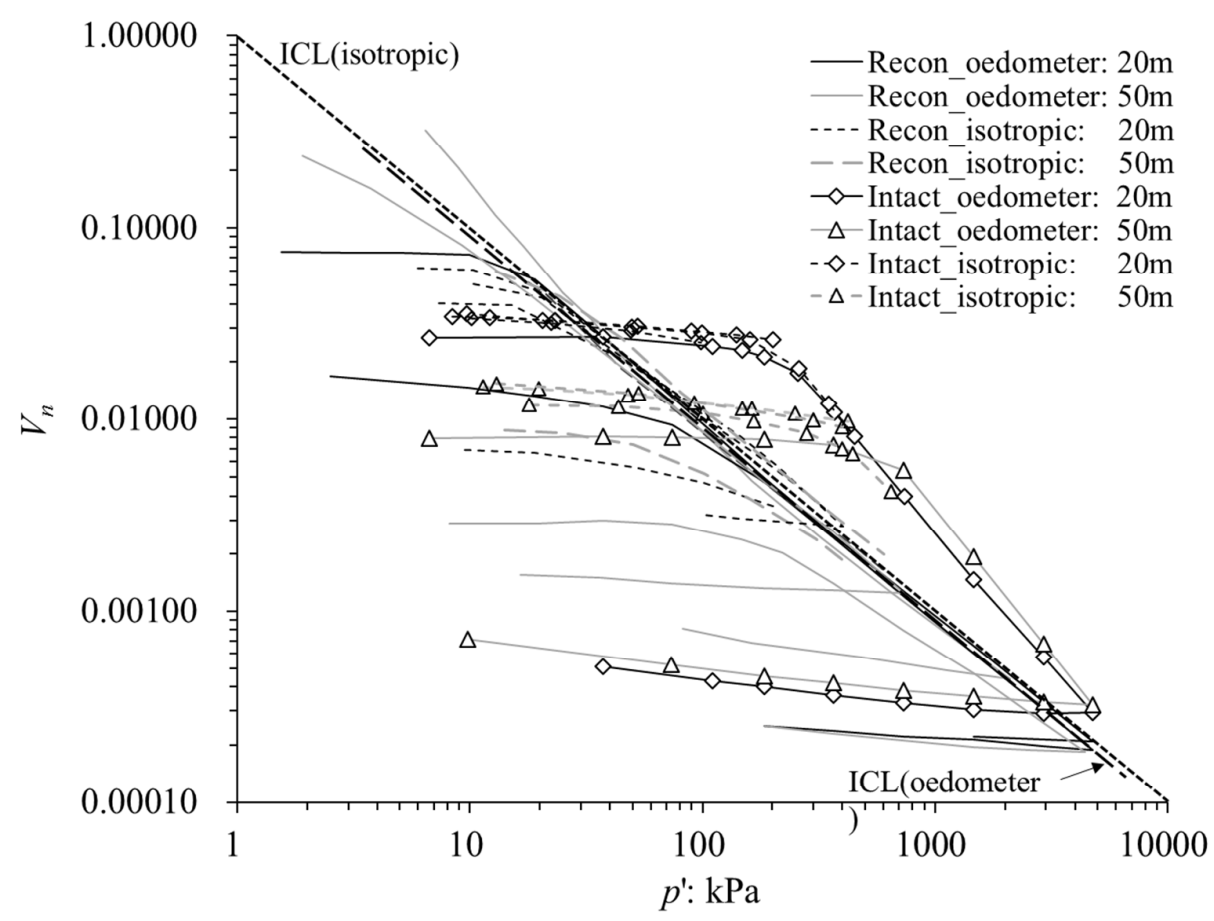

(b)

Fig. 6. Normalized compression data for natural and reconstituted loess (a) using void index, $\mathrm{I}_{\mathrm{v}}$; (b) normalized specific volume, $\mathrm{v}_{\mathrm{n}}$ 


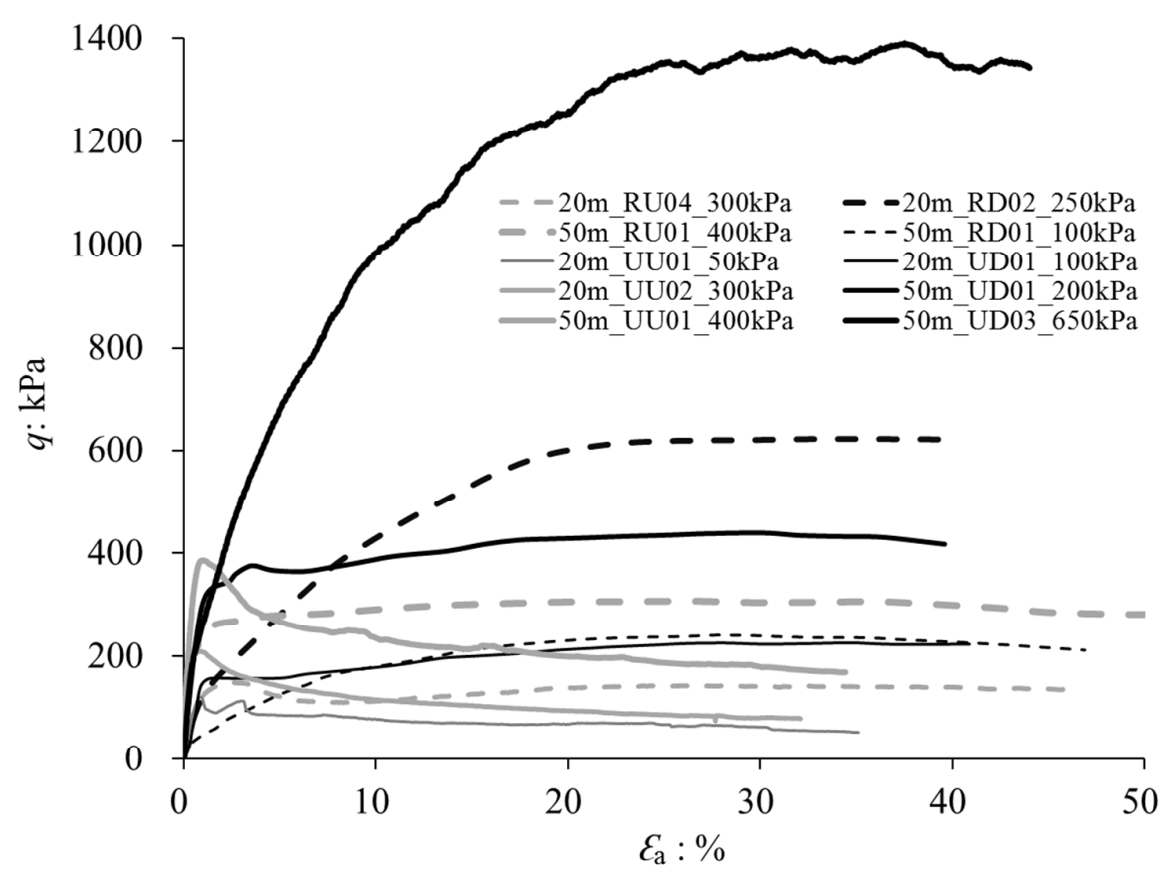

(a)

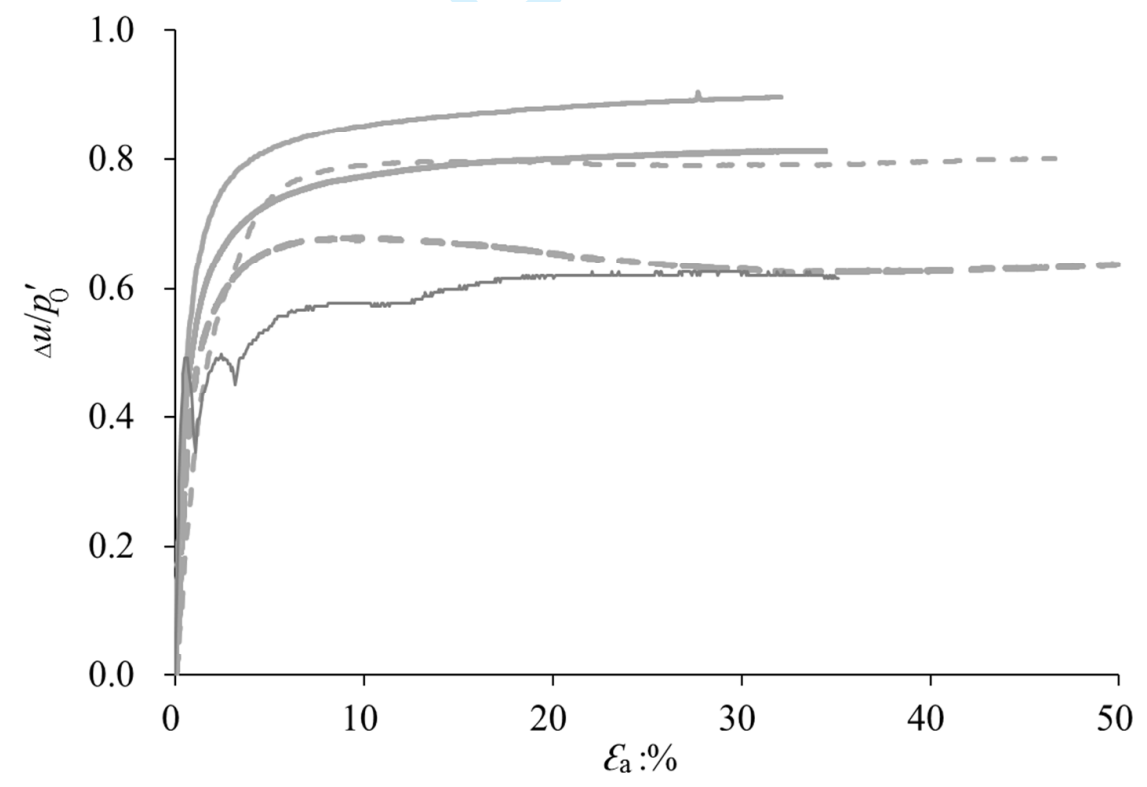

(b) 


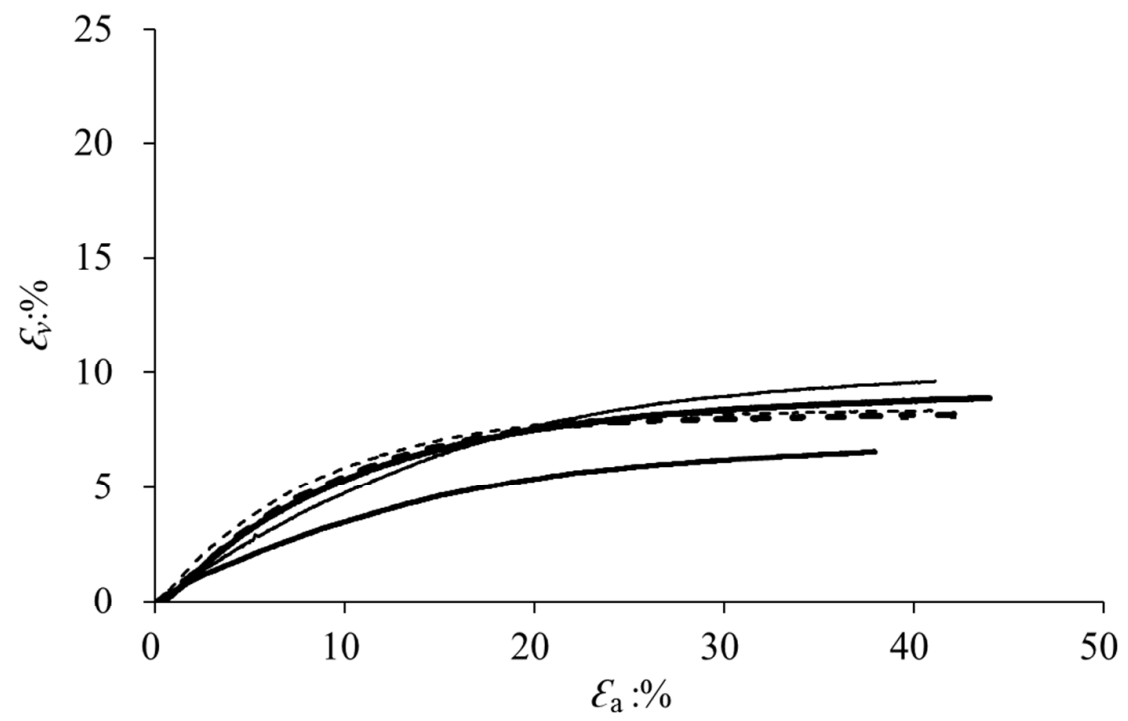

(c)

Fig.7. Typical triaxial test data (a) deviator stress-axial strain curves, (b) pore pressure responses for undrained tests (c) volume changes for drained tests. ( $\mathrm{R}^{* * *}$ reconstituted, $\mathrm{U}^{* * *}$ undisturbed, $* \mathrm{D} * *$ drained, $* \mathrm{U} * *$ undrained) 


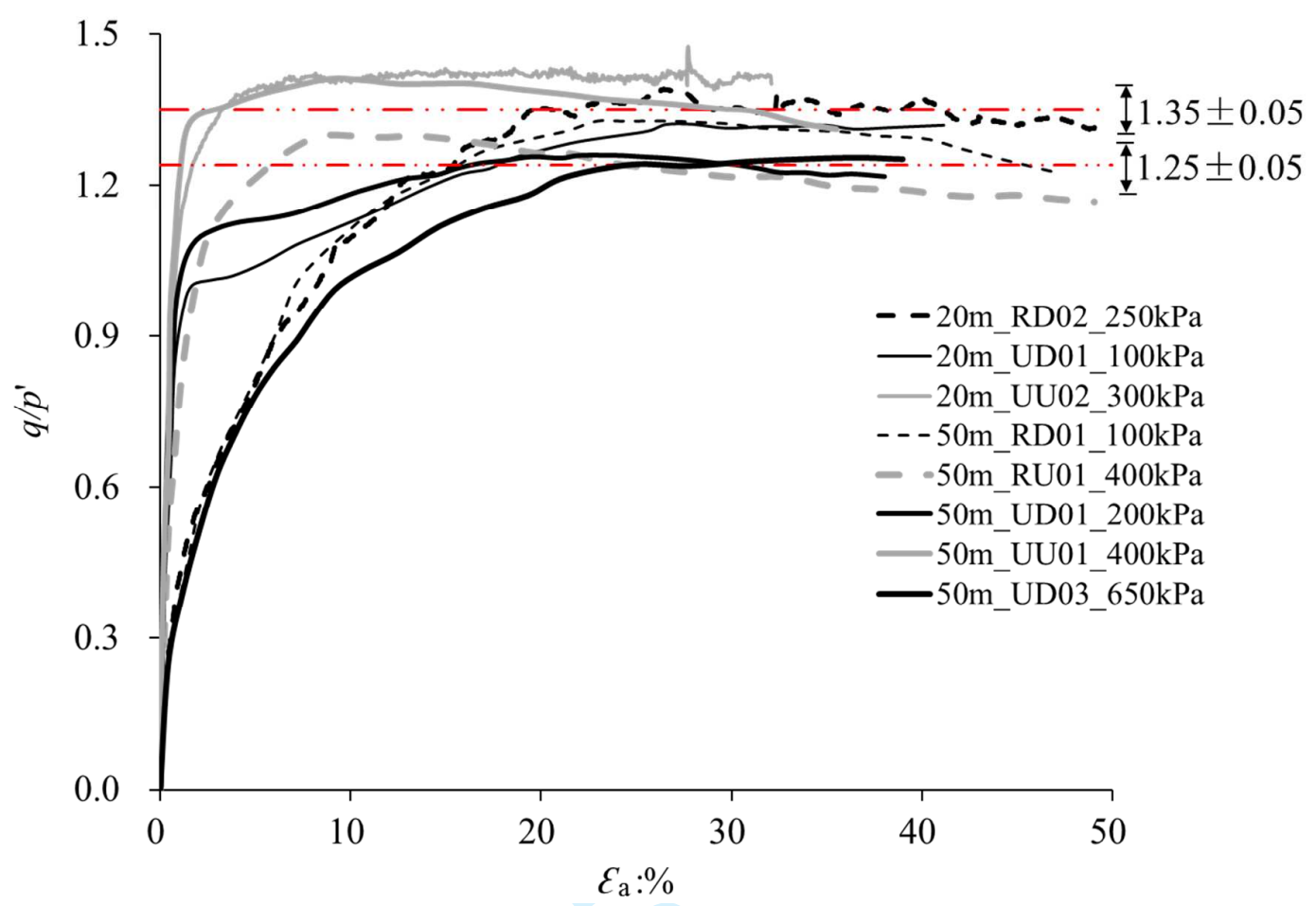

Fig.8. Development of stress ratio for reconstituted and undisturbed specimens 


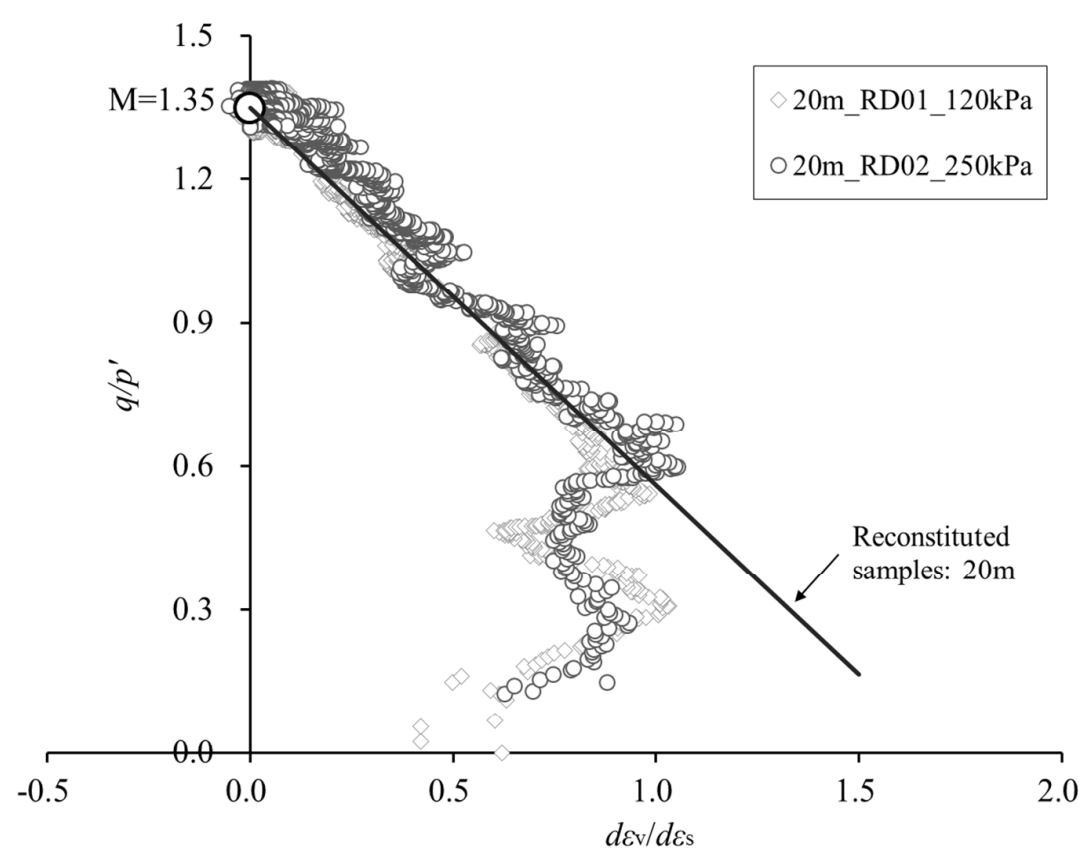

(a)

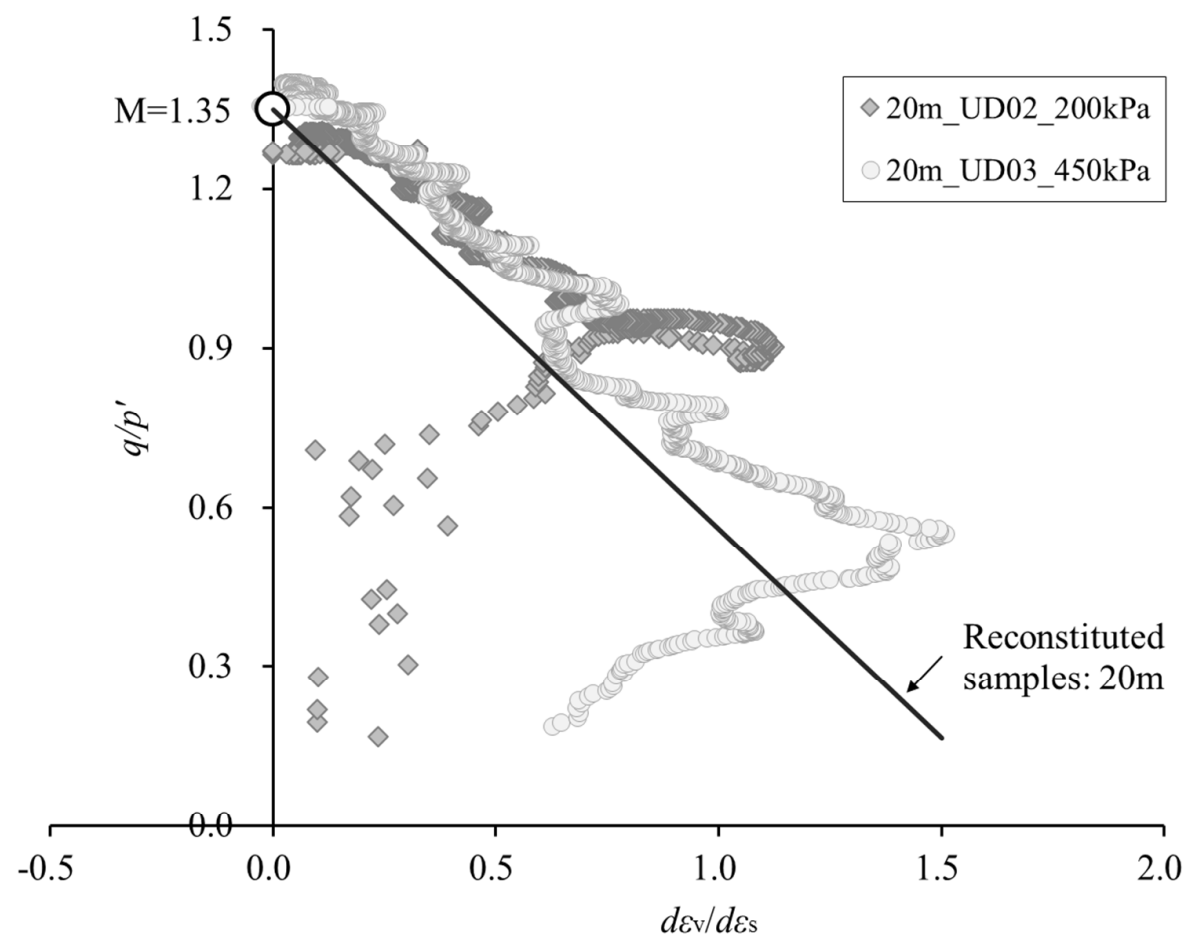

(b) 


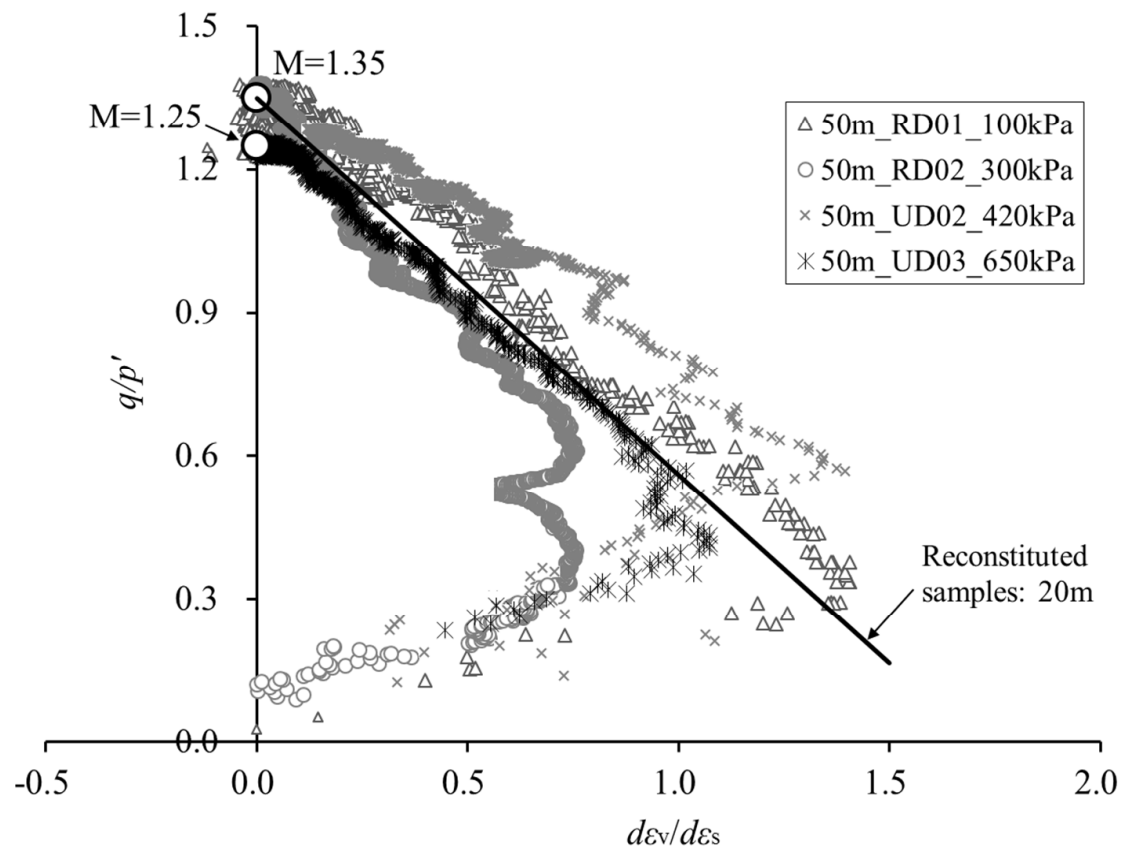

(c)

Fig.9. Stress-dilatancy data for the drained tests on (a) reconstituted specimens $(20 \mathrm{~m})$; (b) undisturbed specimens $(20 \mathrm{~m})$; (c) reconstituted and undisturbed specimens $(50 \mathrm{~m})$ 


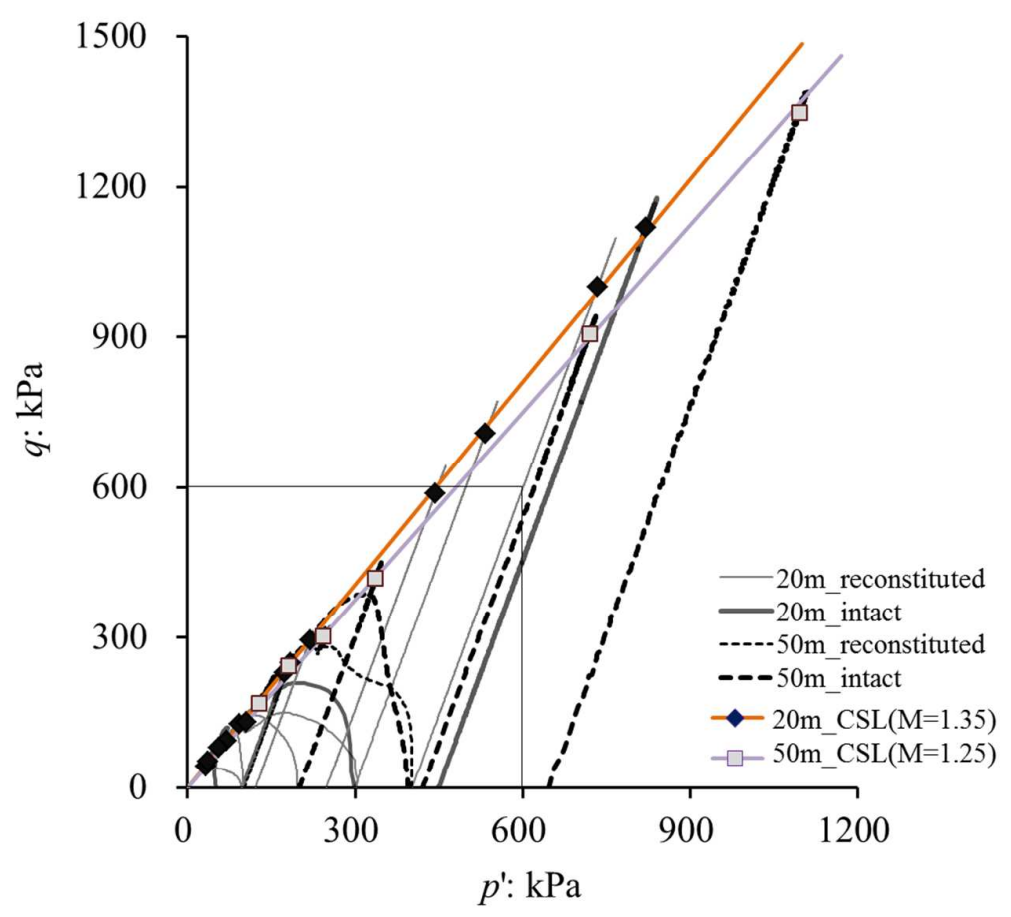

(a)

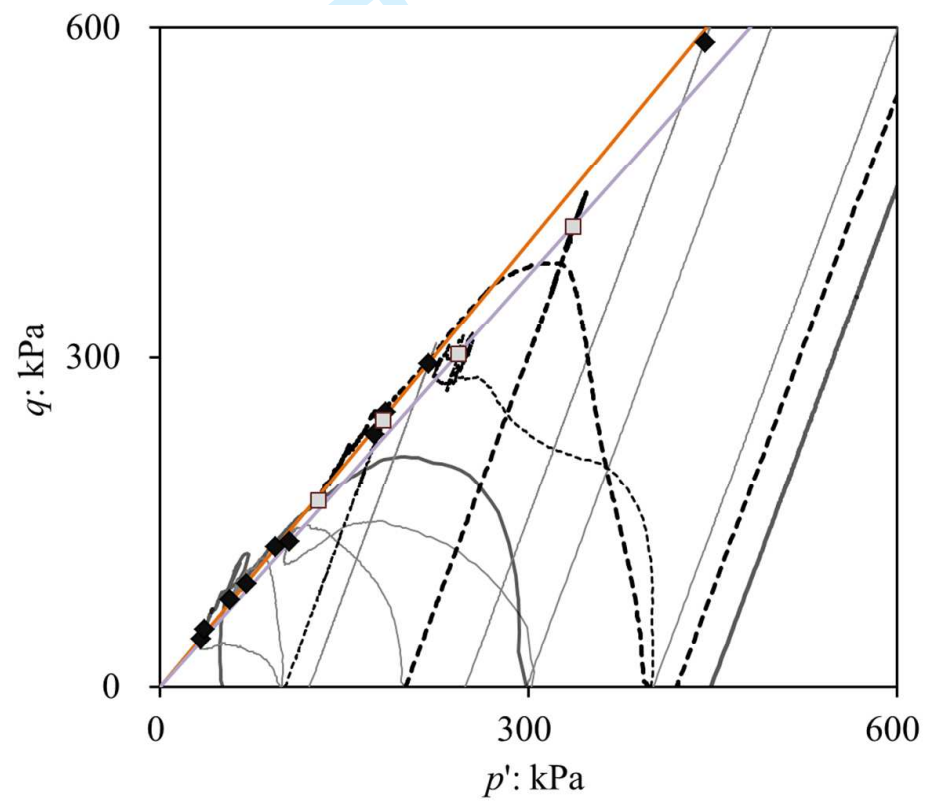

(b)

Fig.10. Stress paths for intact and reconstituted samples (a) entire range of stresses; (b) enlargement for stresses less than $600 \mathrm{kPa}$ 


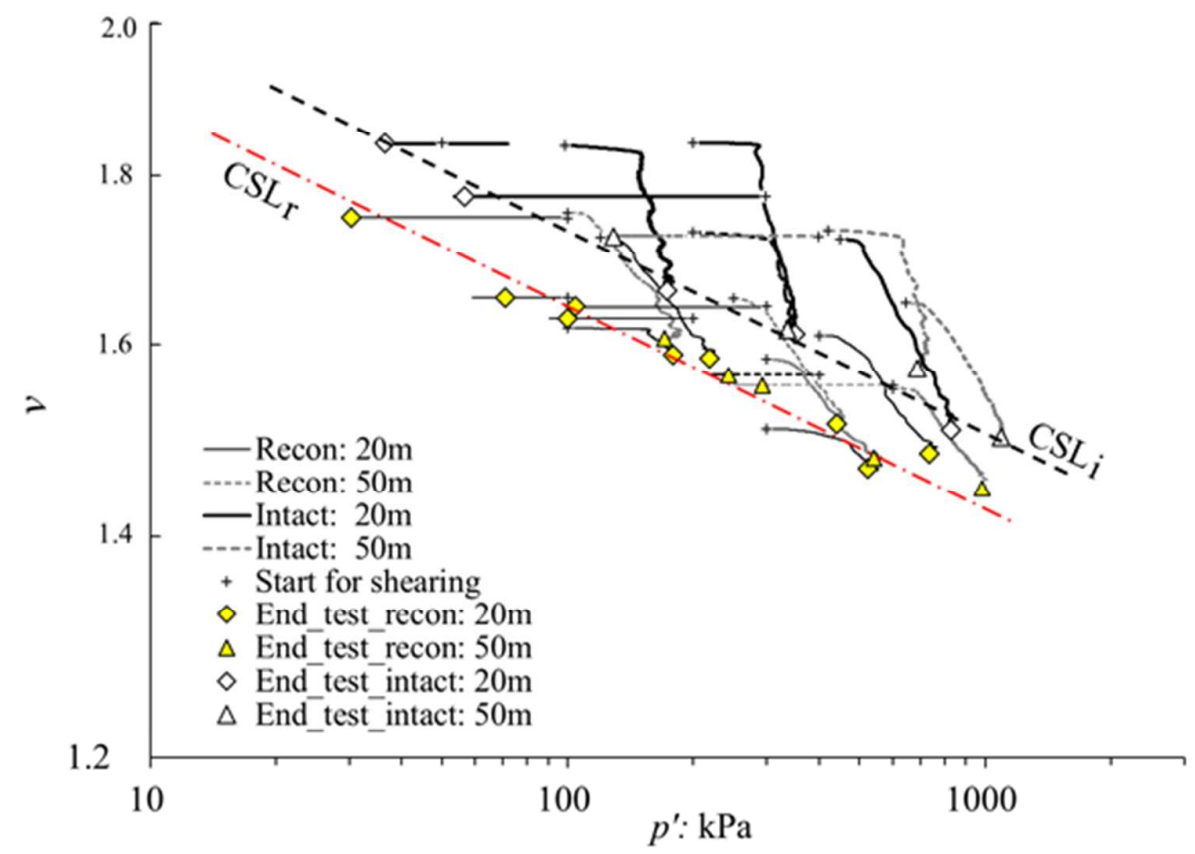

Fig. 11. Critical states line in the volumetric plane 


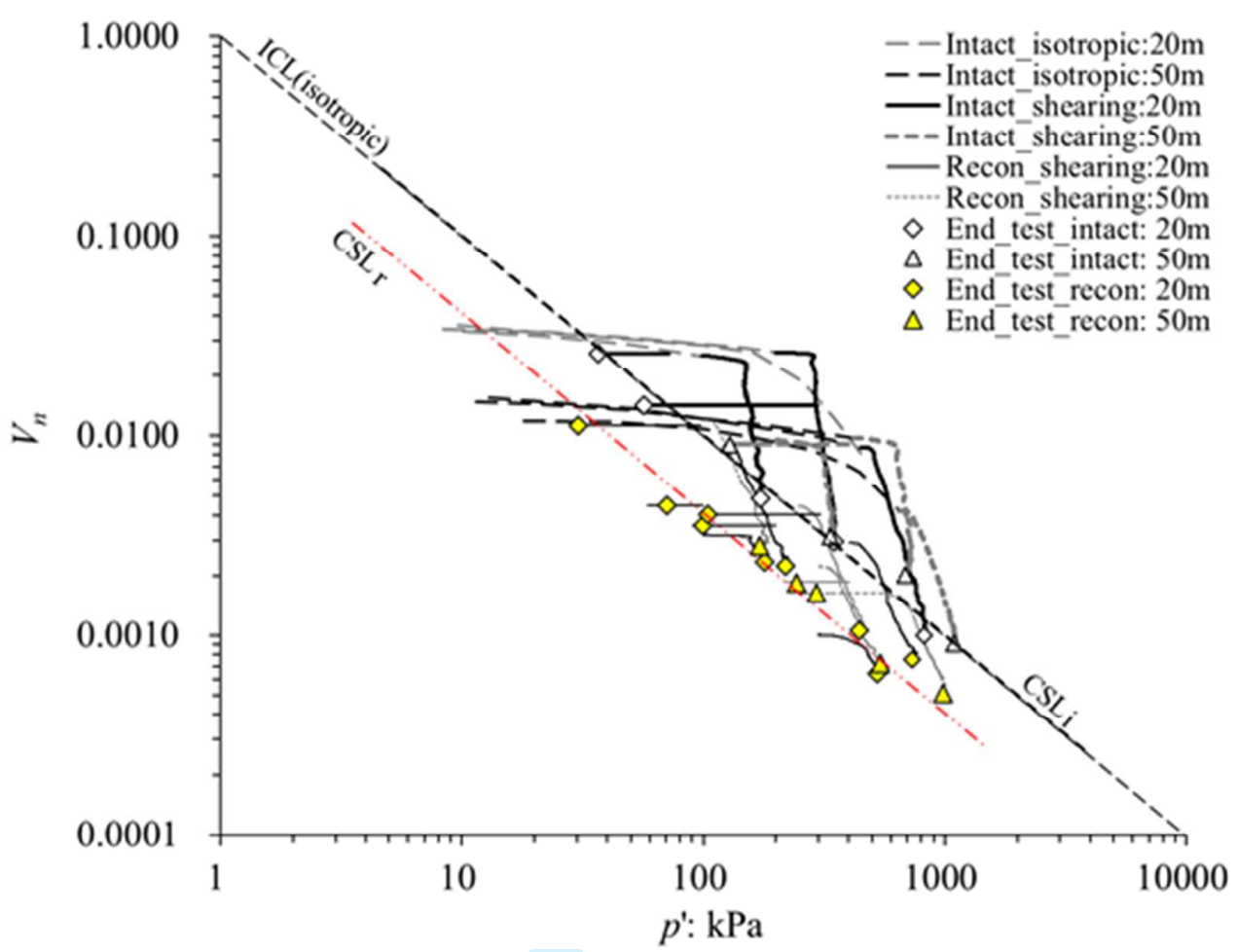

Fig. 12. Critical states line in the normalized volumetric plane. 


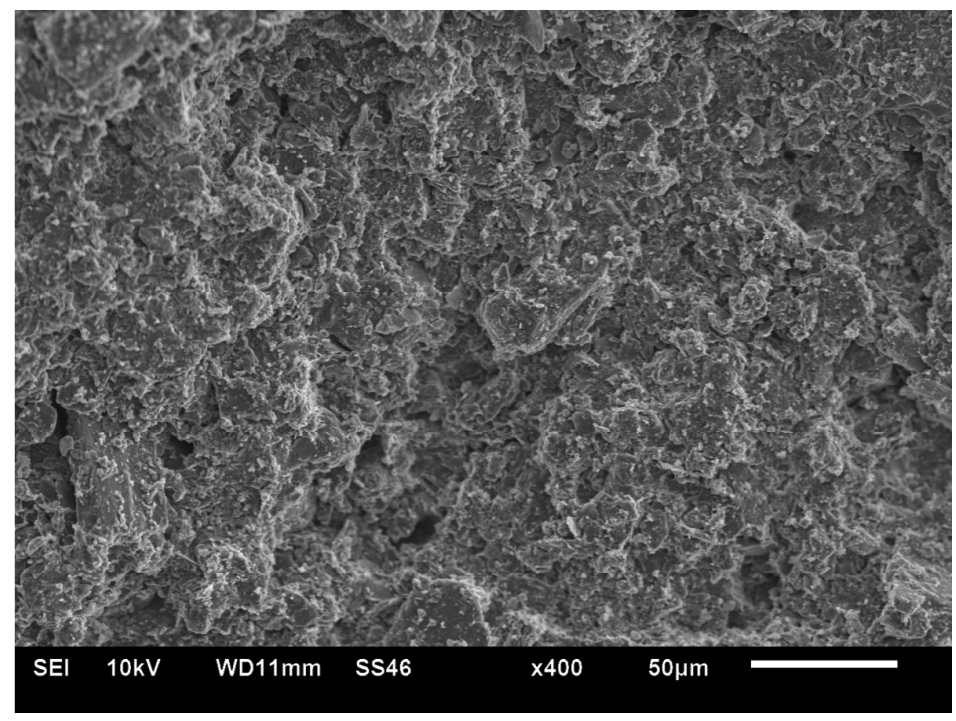

(a) $20 \mathrm{~m}$ intact sample (No. 20m_UD03) horizontal surface

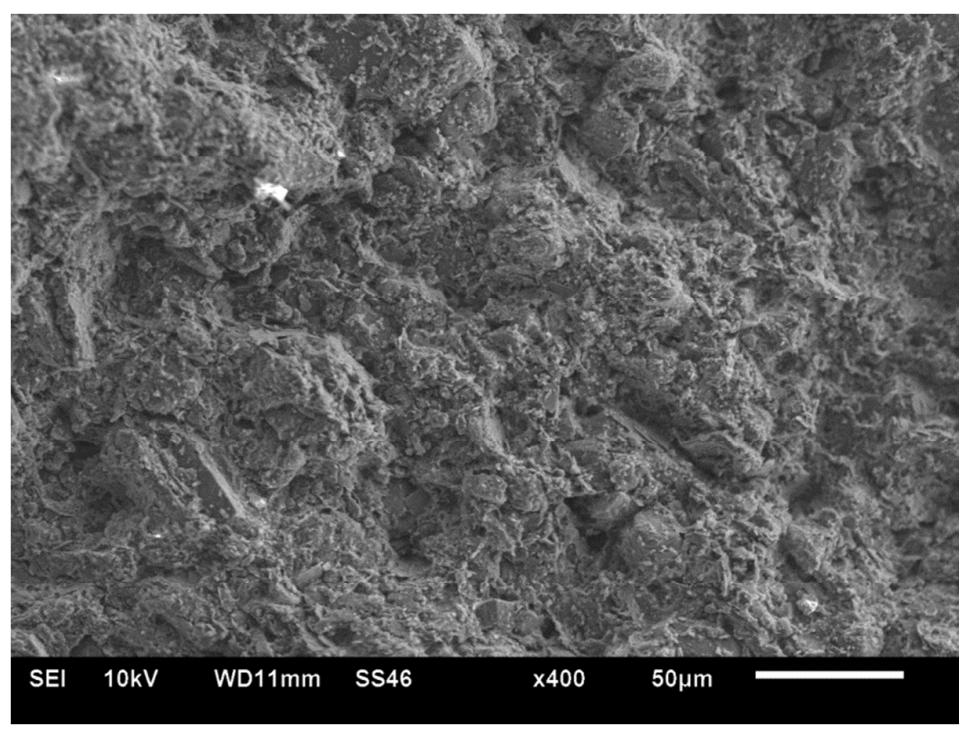

(b) $20 \mathrm{~m}$ intact sample (No. 20m_UD03) vertical surface 


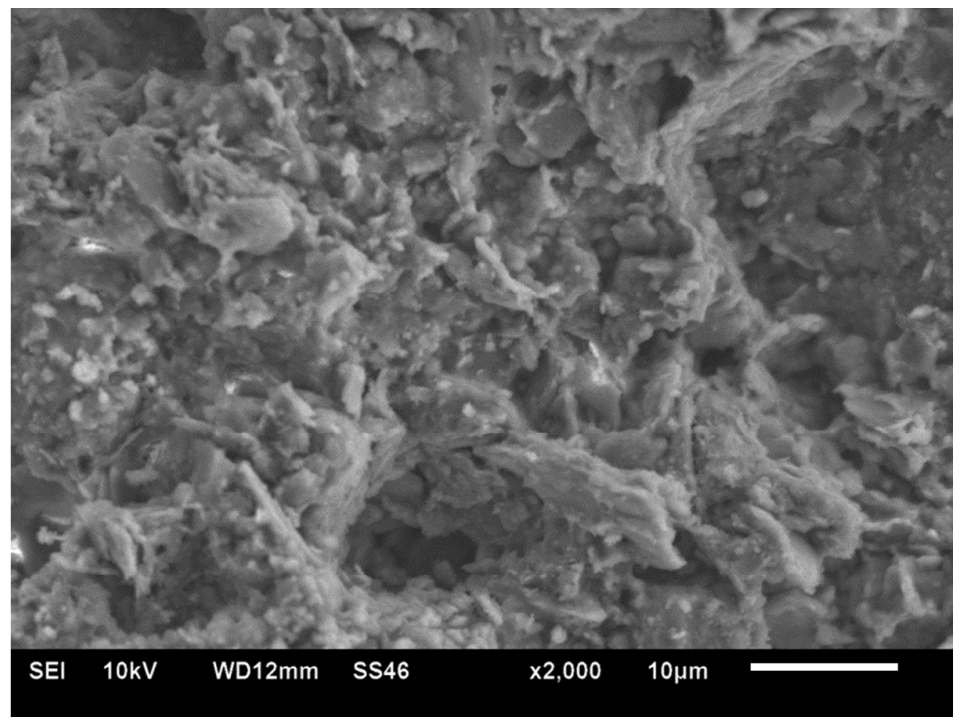

(c) $20 \mathrm{~m}$ intact sample (No. 20m_UD03) showing detail of coating over particles

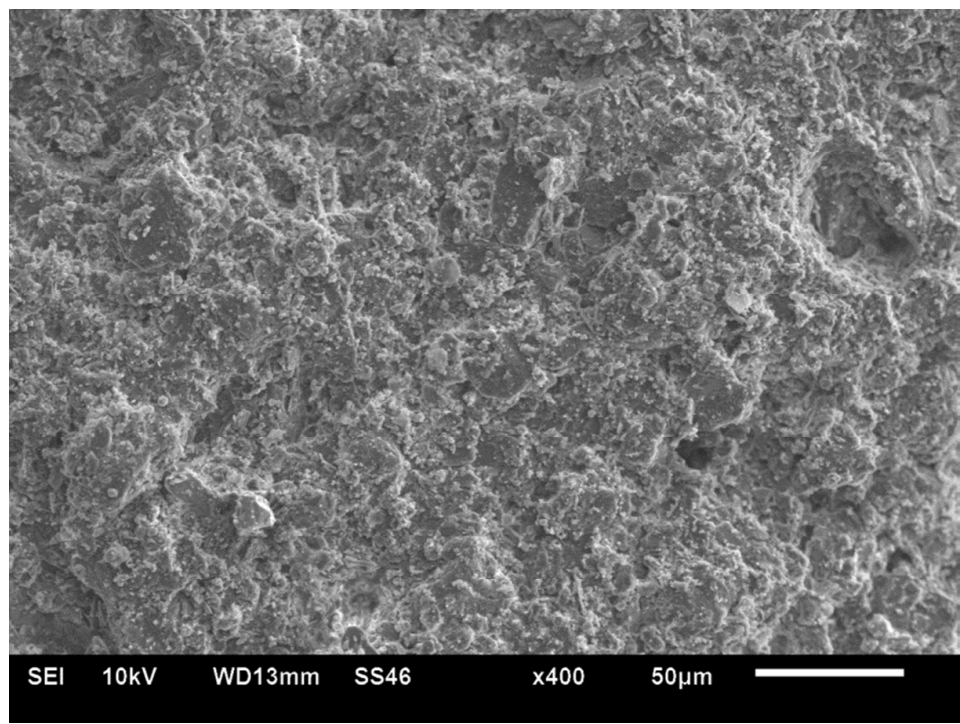

(d) $20 \mathrm{~m}$ reconstituted sample (No. 20m_RD03) horizontal surface 


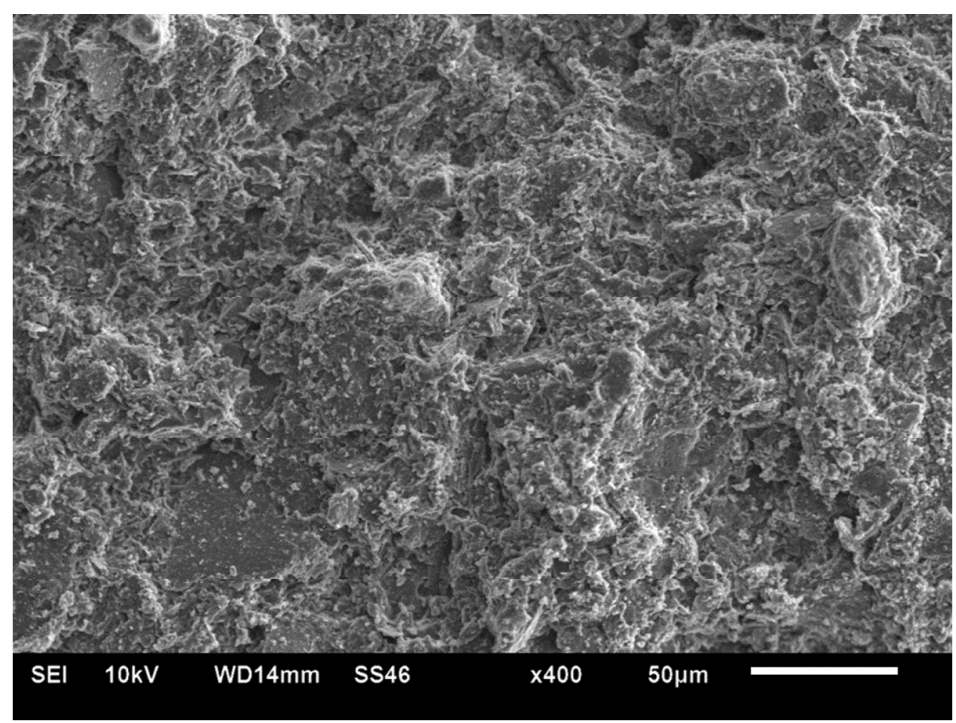

(e) $20 \mathrm{~m}$ reconstituted sample (No. 20m_RD03) vertical surface

Fig.13. SEM images of samples after testing 


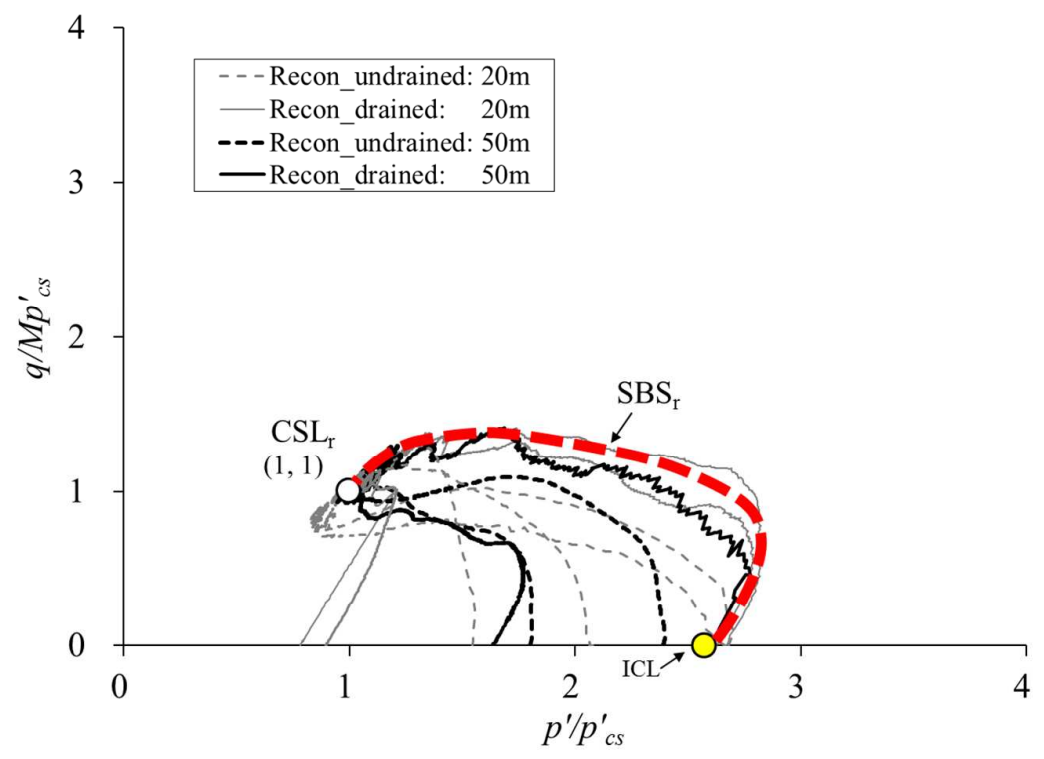

(a) Stress-paths of reconstituted samples normalized by $p_{c s}^{\prime}$ using the intrinsic $C S L$

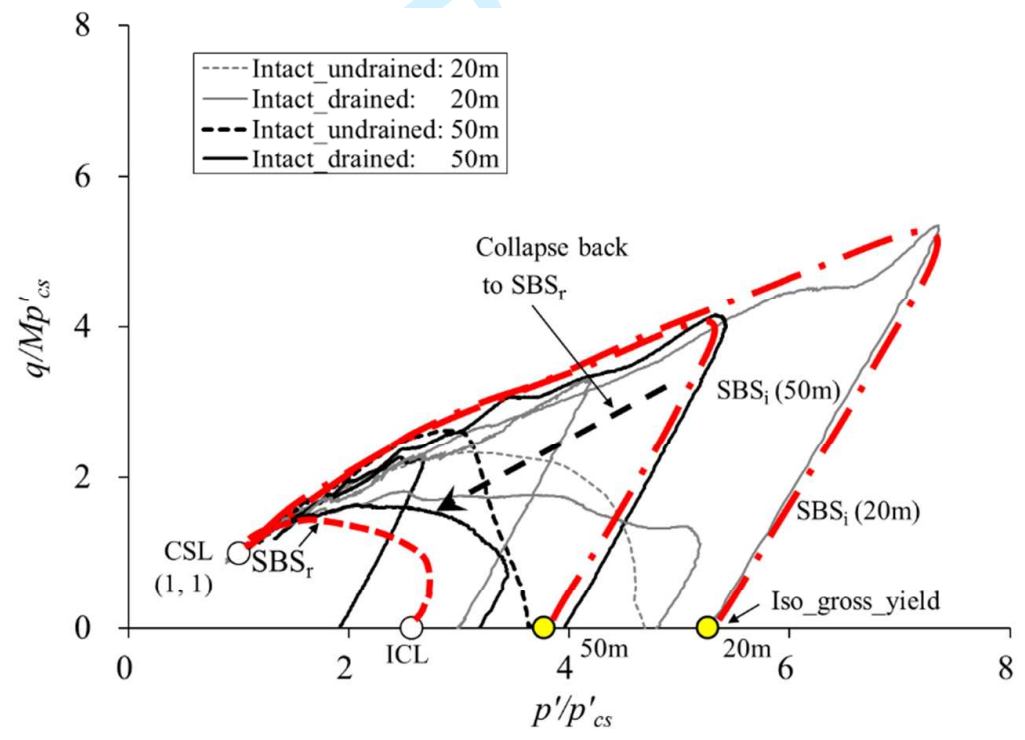

(b) Stress-paths of intact samples normalized by $p_{c S}^{\prime}$ using intact $C S L$ 


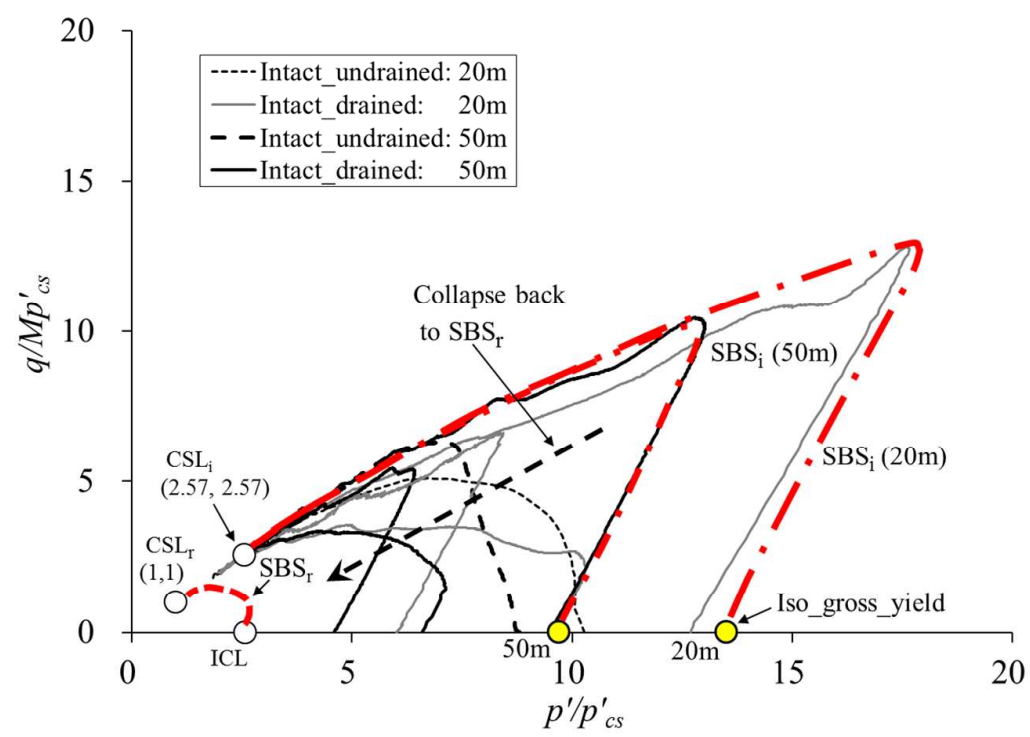

(c) Stress-paths of intact samples normalized by $p_{c s}^{\prime}$ using intrinsic $C S L$

Fig.14. Normalized stress-paths of intact and reconstituted loess 